\title{
Non-Animal Models in Dermatological Research
}

\author{
Elena Dellambra 1,4\#, Teresa Odorisio 1,4\#, Daniela D’Arcangelo 2,4, Cristina M. Failla 3,4 \\ and Antonio Facchiano 2,4 \\ ${ }^{1}$ Laboratory of Molecular and Cell Biology; ${ }^{2}$ Laboratory of Molecular Oncology; ${ }^{3}$ Laboratory of Experimental Immunology; ${ }^{4}$ Working group ALMA, \\ Istituto Dermopatico dell'Immacolata, IDI-IRCCS, Rome, Italy
}

\begin{abstract}
Despite being widely used for basic and preclinical studies in dermatology, available animal models only partly recapitulate human skin features, often leading to disappointing outputs when preclinical results are translated to the clinic. Therefore, the need to develop alternative, non-animal models is widely recognized to more closely recapitulate human skin pathophysiology and to address the pressing ethical demand to reduce the number of animals used for research purposes, following the globally accepted 3Rs principle (Replacement, Reduction, and Refinement). Skin is the outermost organ of the body, and is, as such, easily accessible. Different skin cell types can be propagated in vitro, and skin can be reconstructed for therapeutic transplantation as well as for in vitro modelling of pathophysiological conditions. Bioengineered skin substitutes have been developed and have evolved from elementary to complex systems, more and more closely resembling complete skin architecture and biological responses. In silico analyses take advantage of the huge amount of data already available from human studies to identify and model molecular pathways involved in skin pathophysiology without further animal testing. The present review recapitulates the available non-animal models for dermatological research and sheds light on their prospective technological evolution.
\end{abstract}

\section{Introduction}

The development of alternative models has gained a high priority following the European ban on animal testing for cosmetic ingredients (2009/1223/EU), the REACH guideline for chemicals (2006/1907/EC), and the recommendation to follow the $3 \mathrm{R}$ principle (Replacement, Reduction, Refinement) for research $(2010 / 63 / \mathrm{EU})$. To date, there is an extraordinary variety of non-animal models based on human cells and tissues representing a suitable alternative to replace animal studies for the cosmetic industry. Non-animal models also represent a huge opportunity for pharmaceutical industry since an animal testing ban, while not mandatory at present, is foreseen in the future. However, to formulate pharmaceutical industrial applications, non-animal models do require further development and adaptation. Investments toward improvement of alternative models to animal testing would be profitable for several reasons, including: the relevant reduction of R\&D related costs; the efficacy issue, since animal models do not always appropriately reproduce the human setup; a worldwide visibility related to the cruelty-free and impact-reduction policy distinctive of such strategies. Inter- estingly, the research world, involved as main actor in non-animal model set-up and development, has in general only partial knowledge of the possibilities of alternative methods and does not always apply them as the first choice for scientific investigation, still preferring the use of animal models.

In 1981, a first attempt was made towards reconstituting human skin in vitro for dermatological research. Since then, great efforts have been invested into developing models that more closely recapitulate in vivo skin complexity as tools for functional studies and to test therapeutic approaches. In this review, improvements in non-animal models for dermatological research, especially skin equivalent techniques and in silico tools, will be discussed together with an overview of their application to the main fields of dermatological interest. Moreover, a prospective view of further alternative method development will be given.

\section{Human skin structure}

Human skin is the first line of defense from environmental insults. It covers the whole body and consists of three layered tissues

\footnotetext{
\# contributed equally

Received August 2, 2018; Accepted November 13, 2018;

Epub November 14, 2018; @ The Authors, 2018
}

ALTEX 36(2), 177-202. doi:10.14573/altex.1808022

Correspondence: Cristina M. Failla, Laboratory of Experimental Immunology, IDI-IRCCS, via Monti di Creta 104, 00167 Rome, Italy

(c.failla@idi.it)
This is an Open Access article distributed under the terms of the Creative Commons Attribution 4.0 International license (http://creativecommons.org/licenses/by/4.0/) which permits unrestricted use, distribution and reproduction in any medium, provided the original work is appropriately cited. 


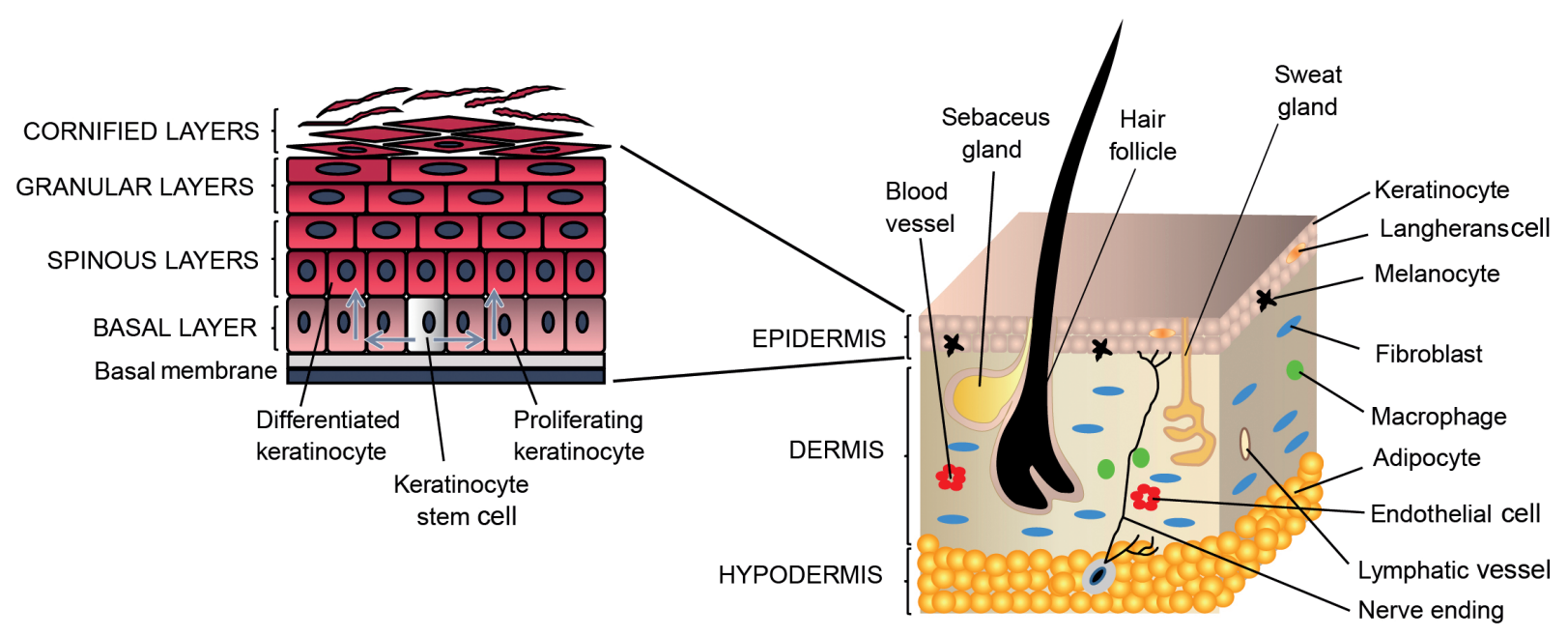

Fig. 1: Schematic human skin organization

Skin is structured into three tissues: the epidermis, the dermis, and the hypodermis. The epidermis is a stratified epithelium constituted of keratinocytes organized into four major layers (basal, spinous, granular, and cornified) at progressive differentiation stages. The epidermis also contains Langerhans cells of the innate immune system and melanocytes, which express melanin. The dermis is mainly populated by fibroblasts releasing the extracellular matrix, and hosts several immune cells, vascular and lymphatic vessels, and nerve endings. The hypodermis is mainly composed of adipocytes. Hair follicles, sebaceous and sweat glands constitute the skin appendages.

differing in cell composition, thickness, strength, and flexibility: the epidermis, the dermis, and the hypodermis (Murphree, 2017) (Fig. 1).

\subsection{The epidermis}

The epidermis is the outermost layer, mainly composed of keratinocytes, organized into four major layers at progressive differentiation stages: basal, spinous, granular, and cornified layers (Candi et al., 2005; Bouwstra and Ponec, 2006; Dellambra and Dimri, 2009; Fuchs, 2016). The basal layer contains proliferating and stem keratinocytes, the latter plays a pivotal role in maintaining epidermal homeostasis and promoting epithelial repair. Keratinocytes of the spinous layer form desmosomes that reinforce intercellular contacts and induce the spinous-like morphology. The granular layer is composed of keratinocytes with an array of filaggrin-rich keratohyalin granules and lamellar granules packed with lipid bilayers. The outermost cornified layer is made of terminally differentiated enucleated cells called corneocytes, surrounded by cross-linked proteins and a covalently bound lipid envelope. Corneocytes are continuously lost and replaced by cells from the strata below. The lipid lamellae in the intercorneocyte space provides the permeation barrier of human skin (Candi et al., 2005; Bouwstra and Ponec, 2006; Dellambra and Dimri, 2009; Fuchs, 2016).

Besides keratinocytes, the epidermis contains melanocytes, localized in the basal layer and producing melanin, which are responsible for skin pigmentation and protect from ultraviolet (UV) radiation (Wang et al., 2016); Merkel cells, residing in the basal layer and contributing to mechano-sensory reception
(Woo et al., 2015); and immature Langerhans cells in the suprabasal layers that provide the first line of immunological defense against infection (Seneschal et al., 2012).

\subsection{The dermis}

The dermis is the connective tissue beneath the epidermis. Epidermal downward projections (rete ridges), and corresponding dermal upward projections (dermal papillae), increase the interaction area between the two layers. The dermis can be divided into papillary and reticular dermis: the papillary dermis is the superficial portion, which is thinner, more vascularized and innervated, with higher cell density and fine collagen bundles; the reticular dermis displays a lower cell density, and thick, well-organized collagen bundles (Sriram et al., 2015; Murphree, 2017). The dermis is mainly populated by fibroblasts. Papillary and reticular fibroblasts manifest distinct morphology, gene expression patterns, and functions (Sriram et al., 2015). The dermis also accommodates immune cells, such as monocytes/macrophages, mast cells, neutrophils and lymphocytes, as well as blood and lymphatic vessel networks, and nerve endings (Sriram et al., 2015; Murphree, 2017).

\subsection{The hypodermis}

The hypodermis is the inner subcutaneous tissue that supports the upper dermal layer and is composed of adipose tissue, mainly consisting of fat droplet-storing adipocytes. This layer stores excess energy as fat, acting also as thermal insulation. Moreover, it provides padding against pressure and shear forces. The hypodermis contains blood and lymphatic vessels, nerve endings, fi- 
broblasts, and mast cells (Dellambra and Dimri, 2009; Murphree, 2017).

\subsection{Skin appendages}

Hair follicles, sebaceous glands, and sweat glands are specialized epidermal structures located in the reticular dermis and hypodermis. Hair follicles are composed of different concentric cell layers. Beyond their relevance in thermoregulation and sensory functions, hair follicles play an important role in wound healing, as they are a supplementary source of keratinocyte stem cells (Fuchs, 2016). Hair follicles also contain sebaceous glands and the entire complex is termed the pilosebaceous unit. Sebaceous glands are branched acinar portions of lipid-producing sebocytes, which release sebum to moisturize the hair and the skin surface (Fuchs, 2016; Murphree, 2017). Sweat glands consist of a coiled secretory intradermal portion and a straight duct that leads up to the epidermis. Sweat glands regulate body temperature by secreting a water-based solution onto the skin surface (Fuchs, 2016; Murphree, 2017).

\section{Animal models in dermatological research: potentials and limitations}

The use of animal models for dermatological research studies has increased enormously in the past decades, giving a strong boost to the comprehension of skin pathophysiological mechanisms and to testing therapeutic approaches at preclinical level (Avci et al., 2013). Animal models have the great advantage of manifesting the complexity of an entire organ and its interactions with other organs. However, besides the ethical concerns related to the use of animals, animal skin only in part recapitulates human skin features, making it often difficult to translate basic and preclinical findings into the clinic. Such differences underline the need for other, more representative and reliable models.

\subsection{Mice and other rodents}

Mice represent the most widely used animal model for pathophysiological studies. They are readily available and easy to handle, their skin shows similarities with the human counterpart, they can be genetically engineered, and they have a short lifespan as compared to larger mammals. Pathological features recapitulating dermatological diseases have been reproduced in the mouse by gene knock-out or knock-in, transgene over-expression, by using mouse strains with spontaneous mutations, or using immunodeficient humanized mice engrafted with human skin (Garcia et al., 2007; Chen and Roop, 2008; Schneider, 2012; Avci et al., 2013). Mice are used in all areas of dermatological interest, from immunological diseases to cancer, skin repair, genetic diseases, and hair disorders (Tab. 1). However, data interpretation is limited by structural, physiological, and molecular differences (Fig. 2). A recent in silico study has identified genetic networks that demonstrate species differences in human skin versus mouse skin (Wu et al., 2017). Such differences explain, at least in part, why results obtained in mouse models can often not be reproduced in the human context. The most obvious difference is that mice and other rodents, such as rats, guinea pigs, and rabbits, have fur covering most of the body, while in humans the ratio between haired and nude skin is much smaller. This feature contributes to making mouse skin more permeable than human skin. Therefore, the skin of nude rodents is more similar to human skin for structure and percutaneous absorption (Jung and Maibach, 2015). Moreover, in mouse skin all three skin layers, i.e., epidermis, dermis, and hypodermis, are thinner and the epidermis does not deepen into the dermis with projections as it does in human skin. Again, the body areas not covered by hair (ears, tail) manifest a thicker epidermis with a higher cell layer number, like human skin (Fig. 2). Rodent skin is detached from the underlying structures and it includes a muscle layer underneath the adipose tissue that is not present in human skin. The muscular layer has an impact on wound closure that in mice is mainly achieved by early contraction, while in humans it relies on keratinocyte proliferation and migration (re-epithelialization). Other differences regard: 1) timing of epidermal renewal and hair follicle cycle, which are much faster in the mouse than in the human (8-10 days versus 26-28 days for epidermal renewal, respectively); 2) immune cell composition; 3) melanocyte distribution. Immune cell differences comprise dendritic cell subtypes with a higher number of antigen presenting dendritic cells expressing $\gamma \delta$ receptor in mouse skin (MacLeod and Havran, 2011). As for melanocytes, they are distributed in the hair follicle and in the epidermal basal layer in human skin, where they interact with keratinocytes, while they are mainly confined to the hair follicles in the mouse. This can be a limit for studies on melanoma development, particularly for UV-inducible melanoma genesis that starts in the epidermis.

Tab. 1: Different animal models and their use in the main fields of dermatological interest

\begin{tabular}{|l|l|l|l|l|l|l|}
\hline Species & Melanoma & $\begin{array}{l}\text { Wound } \\
\text { healing }\end{array}$ & Psoriasis & $\begin{array}{l}\text { Genetic } \\
\text { disorders }\end{array}$ & $\begin{array}{l}\text { Toxicologic } \\
\text { screening }\end{array}$ & Skin aging \\
\hline Rodents & $\mathrm{X}$ & $\mathrm{X}$ & $\mathrm{X}$ & $\mathrm{X}$ & $\mathrm{X}$ & $\mathrm{X}$ \\
\hline Pig & $\mathrm{X}$ & $\mathrm{X}$ & $\mathrm{X}$ & $\mathrm{X}$ & $\mathrm{X}$ & $\mathrm{X}$ \\
\hline Zebrafish & $\mathrm{X}$ & $\mathrm{X}$ & & $\mathrm{X}$ & & \\
\hline Drosophila & $\mathrm{X}$ & $\mathrm{X}$ & & & $\mathrm{X}$ \\
\hline
\end{tabular}




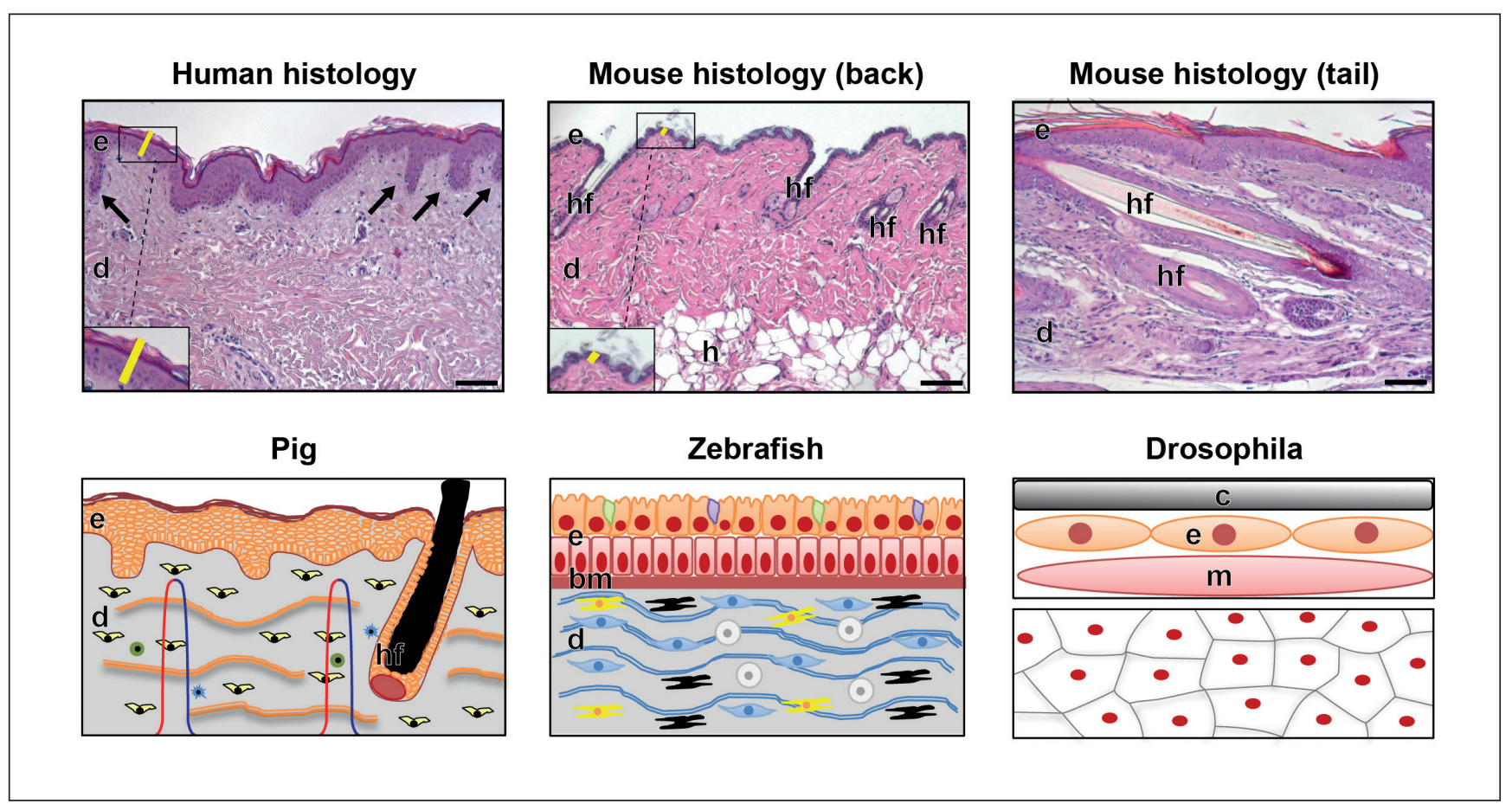

Fig. 2: Features of human and animal model skin

Upper panels: Histological comparison of human skin with mouse back and tail skin. Human skin is much thicker than mouse skin in the epidermal (yellow bars), dermal, and subcutaneous (fat layer) compartments. Moreover, human epidermis has projections (arrows) that protrude into the dermis, unlike mouse skin. In the mouse, hair follicles (hf) are found all over the body, whereas these are generally scarce in human skin. Fur has a protective function and mouse skin has less developed differentiated cell layers forming the epidermal barrier. Mouse tail skin, which has a lower number of hairs, has a thicker epidermis with increased cell layers compared to back skin and a more developed external stratum corneum. e, epidermis; d, dermis; hf, hair follicle. Bars: $50 \mu \mathrm{m}$.

Lower panels: Simplified schematic representation of pig, zebrafish and drosophila skin. Pig skin is very similar to human skin in terms of cell composition, physiology, and thickness, apart from the subcutaneous fat layer, which is thicker in the pig (not shown). The dermis has collagenous bundles in the extracellular matrix (orange strings) released by fibroblasts (yellow cells), is vascularized, and few immune cells, i.e., macrophages (blue cells) and lymphocytes (green cells), are present. Ascending arterioles (red) and descending venules (blue) are also shown. Zebrafish skin is formed by epidermis and dermis separated by a basement membrane. The zebrafish midterm embryo has a bi-layered epidermis containing mucus cells (green) and ionocytes (violet), responsible for ionic reabsorption and acid-base regulation, besides keratinocytes, and a dermis with collagenous fibers (blue strings) released by fibroblasts (blue cells). Pigment cells (chromophores) are melanophores, similar to melanocytes (black), xanthophores (yellow), and iridophores (light grey). Melanophores contribute to the longitudinal dark stripes. In the adult fish, the epidermis is multilayered and covered by scales (not shown). Drosophila skin (upper part) has a single epidermal layer covered by a cuticle. Epidermal cells are attached to a thin basement membrane (basal lamina) overlying muscle cells. The lower part of the Drosophila skin panel represents the larval epidermis observed from outside. Larval epidermis is used to study molecular mechanisms of wound re-epithelialization. e, epidermis; d, dermis; bm, basement membrane; hf, hair follicle; m, muscular layer; c, cuticle.

\subsection{Pigs and large mammals}

Pig skin shares the highest similarity with human skin in terms of anatomy and physiology (Fig. 2). Epidermal and dermal thickness is very similar, while the fat layer is thicker in pig skin. Horny layer lipid composition is similar in pig and human skin; epidermis interdigits with the upper dermal compartment; hair follicles are sparse in both species; collagen and elastin dermal content is analogous. Moreover, immune cell composition and melanocyte distribution are similar, and pig skin adheres to underlying tissue as human skin does. Owing to these similarities, pig is a model for studies in all dermatological fields, such as skin surgery, melanoma research, wound healing and therapies, microbiology, vitiligo and depigmentation (Tab. 1) (Bourneuf, 2017; Irons et al., 2018; Klein et al., 2018). In particular, the porcine model represents the golden standard for preclinical wound healing studies, as the concordance of results obtained in human and pig wound therapy is the highest compared with other animal models (Sullivan et al., 2001). The main limitation in working with pigs and other big mammals is their dimension, which impacts on costs, numbers of animals to be used per experimental group, difficulty in manipulation, and in genetic engineering. Miniature pigs can be used as an alternative model, as they maintain the benefits of structural and physiological similarities with human skin. 


\subsection{Zebrafish}

The small, freshwater fish Danio rerio, known as zebrafish for its stripped tegument, is commonly used for basic research and disease model studies. Several features make zebrafish a valuable research system, such as genome similarity to humans, easy genetic manipulation, embryonic transparency, rapid embryonic development, and large number of offspring. Another advantage is the lower neurological development compared to mammals, likely implying reduced pain perception and stress susceptibility. Zebrafish is used as a model system for both skin biology and pathology (Li and Uitto, 2014). Its skin is composed of an epidermis and a collagenous dermis, separated by a basement membrane (Fig. 2). Zebrafish is used for wound healing studies, as major events found in mammalian skin repair are present (Richardson et al., 2013), although the surrounding liquid environment represents an objective major difference to humans. Zebrafish is extensively used also in studies regarding melanogenesis, pigment disorders, and melanoma (Choi et al., 2007; van Rooijen et al., 2017) (Tab. 1). Indeed, black pigment cells originating from the neural crest (melanophores) are present in the dermis and behave similarly to human melanocytes. As for melanoma studies, genetically modified zebrafish expressing melanoma oncogenes recapitulate melanoma genesis and development. Heritable skin diseases affecting cell adhesion and keratinization disorders were also reproduced in zebrafish ( $\mathrm{Li}$ et al., 2011; Li and Uitto, 2014). Limitations in using zebrafish as a skin animal model include the lack of an epidermal barrier and of appendages, and the presence of scales in the adult fish. However, the lack of epidermal barrier allows for systemic drug screening by simply adding compounds to the water.

\subsection{Drosophila}

Despite being so far away from humans phylogenetically, the fruit fly Drosophila melanogaster is used as an animal model to elucidate molecular networks underlying skin physiology (Tab. 1). Drosophila has a single-layered epidermis (Fig. 2) and has

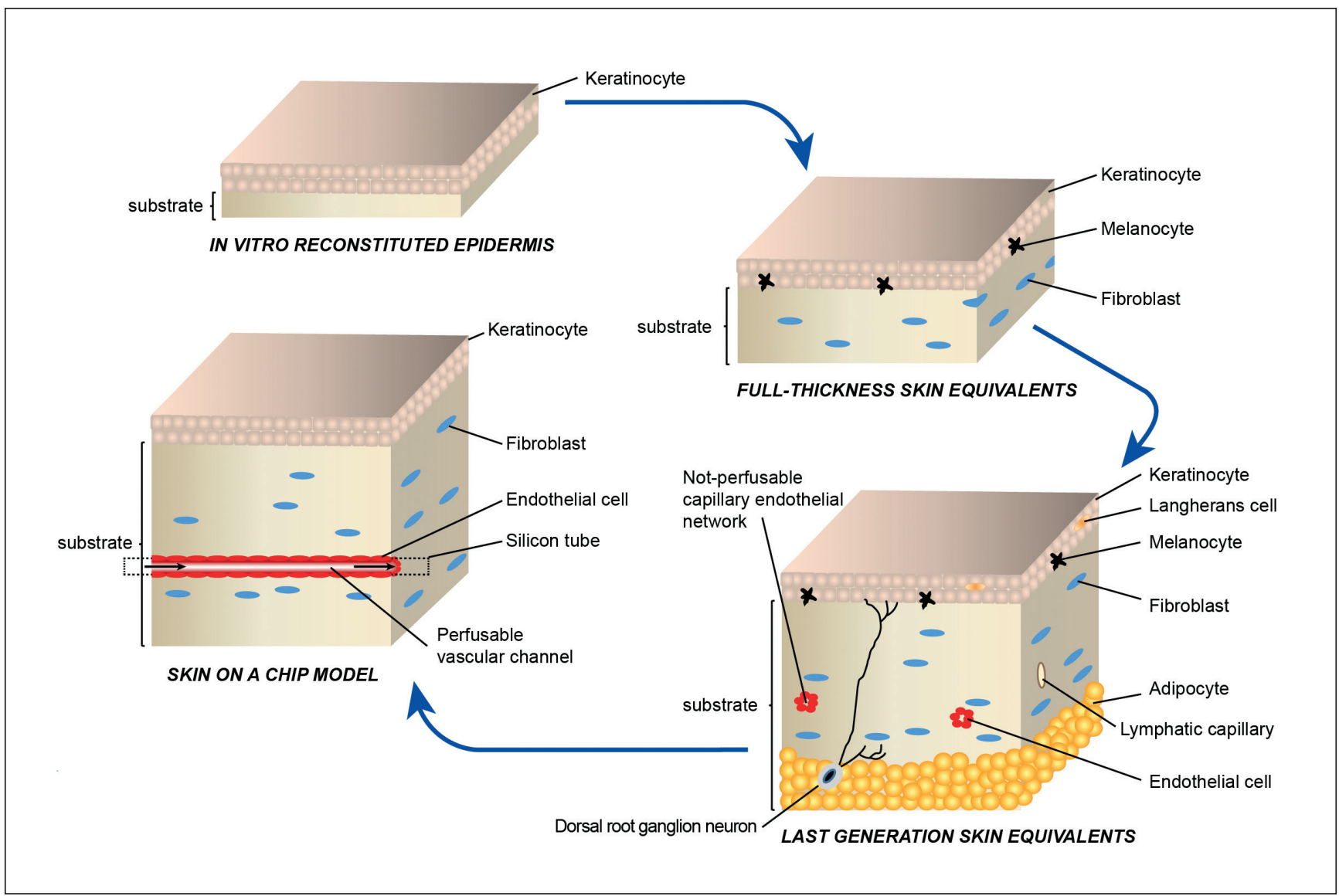

Fig. 3: Evolution of in vitro skin models: from reconstituted epidermis to "skin-on-a-chip"

Epidermis reconstituted by seeding primary keratinocytes on a biological matrix was the first in vitro 3-D model. Full-thickness skin equivalents are obtained by seeding keratinocytes on a de-epidermized dermis or on biodegradable polymer substrates containing human dermal fibroblasts. Melanocytes can also be added by seeding them with keratinocytes. Latest generation skin equivalents incorporate additional skin cell types. Microfluidic platforms have been developed to create "skin-on-a-chip" models: perfusable skin equivalents with endothelial cell-coated wires within the dermal compartment attached to silicone tubes and a peristaltic pump. These skin equivalents within the microfluidic device allow development of "skin-on-a-chip" models of growing complexity containing other skin cell types. 
been widely used for studies on wound closure. Indeed, several insights into the molecular mechanisms underlying epithelial cell behavior in skin repair were obtained using the Drosophila larval dorsal closure model (Matsubayashi and Millard, 2016). Other dermatological fields using fruit fly models are aging (Scherfer et al., 2013) and immune disorders (Bergman et al., 2017). Moreover, Drosophila was also used to identify molecular mechanisms underlying human genetic skin diseases (Bohnekamp et al., 2015). Drosophila models are convenient as they are genetically tractable and, due to the large number of offspring generated, allow high-throughput analysis. However, transferring findings to human dermatological diseases is limited by the structural and physiological differences to human skin.

\section{Skin equivalents}

Tissue-engineered human skin equivalents have been developed to reproduce key structural and functional properties of the skin in vitro. They have been widely used for studies on skin homeostasis and its alterations, and for developing therapeutic tools to be applied to large and chronic skin lesions (O'Connor et al., 1981; Gallico et al., 1984; Cuono et al., 1986; Pellegrini et al., 1999; Guerra et al., 2009; Martínez-Santamaría et al., 2012) (Fig. 3).

\subsection{In vitro reconstituted epidermis}

Epidermal equivalents composed of keratinocytes were the first in vitro tool to be generated (O'Connor et al., 1981). Human keratinocytes can be isolated from a small skin biopsy and serially propagated in vitro (Rheinwald and Green, 1975). They recon- stitute sheets of stratified epithelia that retain biochemical and histological characteristics, as well as differentiation features of the original donor site (Rheinwald and Green, 1975; Gallico and O'Connor, 1985). Seeding keratinocytes on biological matrices enhances the performance of in vitro reconstituted epidermis. For instance, a fibrin substrate allows keratinocyte stem cell preservation (Pellegrini et al., 1999; Ronfard et al., 2000; Panacchia et al., 2010) and growth factor delivery (Guerra et al., 2009; Panacchia et al., 2010). However, an authentic dermis is required for reproducible cell engraftment and improvement of histological quality of the regenerated skin, as demonstrated by several clinical trials (Cuono et al., 1986; Pellegrini et al., 1999; Ronfard et al., 2000).

\subsection{Full-thickness skin equivalents}

To overcome the limits of reconstituted epidermis, three-dimensional organotypic models have been developed. Fullthickness skin equivalents are obtained by seeding primary keratinocytes on a de-epidermized dermis (el-Ghalbzouri et al., 2002; Lee and Cho, 2005) or on biodegradable polymer substrates incorporating human dermal fibroblasts. Substrates can be of natural origin, such as hyaluronic acid (Harris et al., 1999; Caravaggi et al., 2003), fibrin (Pellegrini et al., 1999; Ronfard et al., 2000; Llames et al., 2004; Panacchia et al., 2010; Sriram et al., 2018), collagen (Asselineau and Prunieras, 1984; Veves et al., 2001; Campitiello et al., 2005; Tremblay et al., 2005; Maurelli et al., 2006), silk-collagen (Bellas et al., 2012; Lightfoot et al., 2018), or can be synthetic hydrogels (Marston et al., 2003; Kao et al., 2009) that undergo fast polymerization when fibroblasts are mixed with the precursor solution before gelling. The use of fibrin or of a composite silk-col-

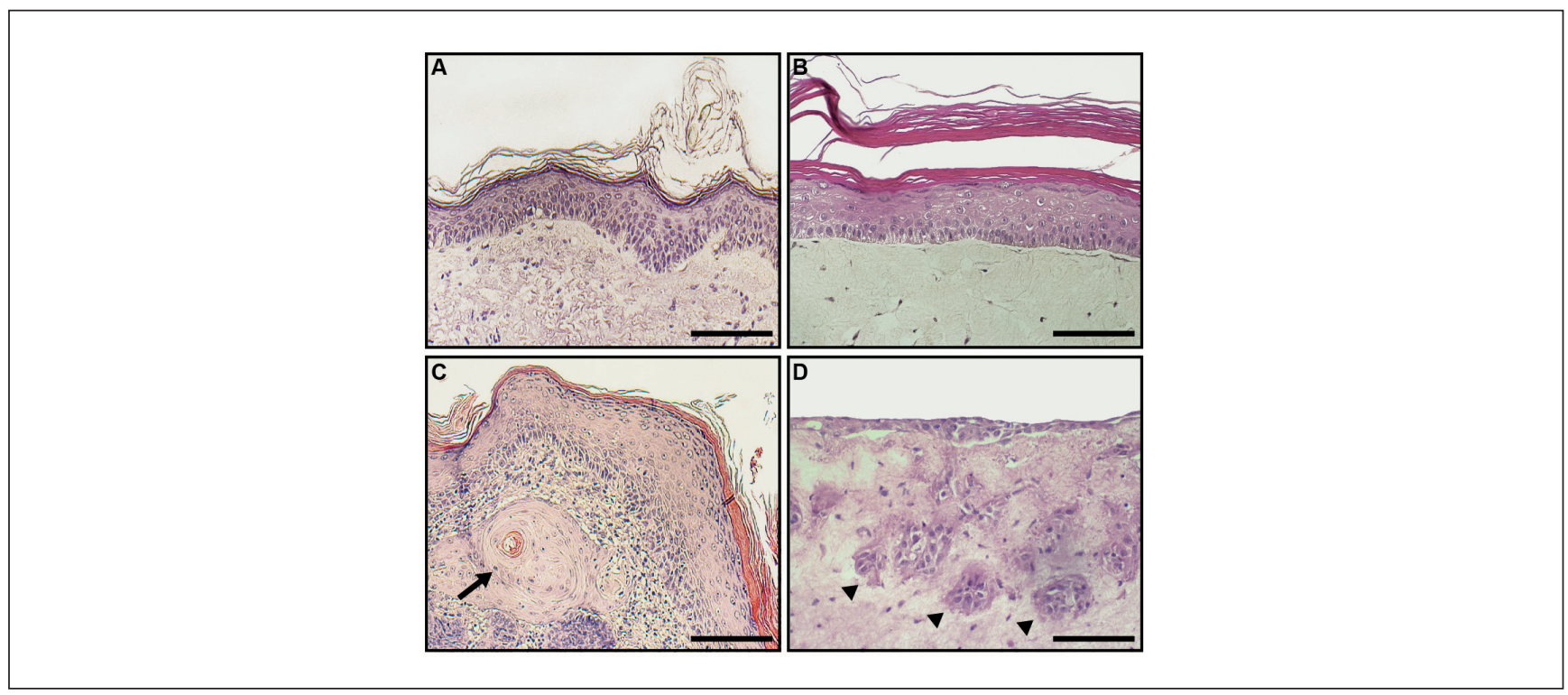

Fig. 4: Histological comparison of human skin and full-thickness skin equivalents

Histological staining of human skin specimen (A) and squamous-cell carcinoma (SCC) sample (C), and in vitro skin equivalents generated by seeding normal human keratinocytes (B) or SCC keratinocytes (D) onto fibroblast-containing collagen gel. Arrow indicates a "horny pearl" in the skin dermis. Arrowheads indicate clusters of tumor cells in the dermal compartment of the skin equivalents. Bars: $200 \mu \mathrm{m}$. 
lagen matrix should be preferred to collagen-based matrices to overcome dermal matrix shrinkage occurring in long-lasting cultures (Lightfoot et al., 2018; Sriram et al., 2018). Skin equivalents are exposed at the air-liquid interface to promote full epidermal differentiation and stratification (Asselineau and Prunieras, 1984; Bernerd and Asselineau, 1998; Maurelli et al., 2006) (Fig. 4A and B). Therefore, they are composed of an organized basal layer with reconstituted dermo-epidermal junctions and several suprabasal layers, from spinous to cornified, with keratinocytes expressing proliferation and/or differentiation markers (Asselineau and Prunieras, 1984; Ponec et al., 1997; Boelsma et al., 2000; el-Ghalbzouri et al., 2002; Panacchia et al., 2010). Nevertheless, these skin equivalents are more permeable than native human skin (Ponec et al., 1997; Bouwstra and Ponec, 2006). Melanocytes may be co-seeded with keratinocytes; they integrate as single cells at the epidermal basal layer, reproducing their physiological distribution (Duval et al., 2001; Bondanza et al., 2007).

Besides their application in the clinical setting as wound coverage, these skin equivalents have been widely used to investigate cellular and molecular mechanisms regulating cutaneous pathophysiology, as discussed below. Commercially available full-thickness skin equivalents have become the alternative to animal models for research and development applications in the cosmetic industry (Böttcher-Haberzeth et al., 2010; Brohem et al., 2011; Groeber et al., 2011; Zhang and Michniak-Kohn, 2012).

\subsection{Latest generation skin equivalents}

Latest generation skin equivalents have been produced by incorporating additional cell types or skin appendages into full-thickness skin equivalents. Mature adipocytes are successfully co-cultured with fibroblasts and keratinocytes to improve the balance between epidermal proliferation and differentiation, and to develop a more efficient epidermal barrier (Trottier et al., 2008; Bellas et al., 2012; Delort et al., 2013; Monfort et al., 2013; Huber et al., 2016). Skin equivalents containing adipocytes are also a useful tool to insert hair follicles that are partly hosted in the adipose tissue in vivo. New hair follicles can be generated by bulge-derived epithelial stem cells cultured in proximity of "inductive" follicular dermal papilla cells (Stenn and Cotsarelis, 2005). Three-dimensional spheroid cultures of dermal papillae implanted in human skin and grafted on SCID mice are able to induce de novo hair follicle generation in vivo (Higgins et al., 2013). The same procedure could be reasonably applied in vitro to induce hair follicle formation by inserting spheroids into bulge cell-populated skin equivalents. Recently, an "endogenous" human skin equivalent was generated by using a dynamic spinner culture of fibroblasts embedded in a temporary scaffold made of gelatin microspheres. The gelatin microscaffold is slowly degraded while fibroblasts assemble their own extracellular matrix. This new microenvironment promotes the morphogenesis of follicle-like structures in vitro, in the absence of dermal papilla cells, and it also improves epidermal barrier function (Casale et al., 2016).
As for immunological cells, CD34-positive hematopoietic progenitor cells have been cultured in skin equivalents. Following treatment with defined cytokine cocktails, these cells are able to differentiate into Langerhans cells and to properly localize in suprabasal layers (Régnier et al., 1997; Facy et al., 2005).

The major weakness of skin equivalents is their lack of a functional vascular system. Nutrients, oxygen supply, and metabolic by-product removal is achieved by manual media changes, leading to periodic fluctuations in culture medium composition (Bauwens et al., 2005; Zhao et al., 2008). Avascular skin equivalents cannot be used as models for studying key features of diseased skin, such as trafficking of leukocytes across vessel endothelium, or for evaluating transdermal drug penetration into the blood stream and/or skin localization of an intravenously administered substance. In 1998, the first skin equivalent with a capillary-like network was obtained by co-culturing keratinocytes, fibroblasts, and umbilical vein endothelial cells (HUVEC) in a collagen biopolymer (Black et al., 1998). Skin equivalents with endothelial cells have been mainly used in a clinical setting to improve graft uptake, or employed to test angiogenic and angiostatic drugs (Hudon et al., 2003; Schechner et al., 2003). To allow long-term analyses, modifications have been introduced to this basic setting. Networks with both lateral and vertical vessel expansion were obtained using an extracellular matrix of human origin with dermal microvascular endothelial cells isolated from the same skin biopsy from which keratinocytes and fibroblasts were derived (Ponec et al., 2004). A fibroblast-derived extracellular matrix produced after vitamin-C treatment has been found to be essential for correct capillary development (Berthod et al., 2006). Moreover, co-culturing endothelial cells and adipose-derived stem cells in fibrin gels induces formation of a stabilized vascular network. Notably, adipose-derived stem cells acquire typical features of pericytes, the smooth muscle cells surrounding vessels (Rohringer et al., 2014). Lymphatic capillaries have been generated by using three-dimensional hydrogels (Marino et al., 2014). To generate vascularized tissues, decellularized porcine small bowel segments have been also used, as they preserve a collagen matrix scaffold with structures of the native vascular network. This scaffold is repopulated with allogeneic porcine endothelial progenitor cells that achieve typical endothelial differentiation features, are vital for up to 3 weeks post reconstitution, and form a vascular network (Mertsching et al., 2005; Schanz et al., 2010). Groeber and co-workers employed a model in which the decellularized porcine jejunum segment, physiologically supplied by a single artery-vein-pair, was reseeded with human dermal microvascular endothelial cells and perfused by using a bioreactor system generating a physiological pulsatile pressure (Groeber et al., 2013). The same porcine scaffold was used to generate a vascularized skin equivalent by seeding human fibroblasts and keratinocytes on its surface. The bioreactor system supports the skin equivalent under submerged conditions or at the air-liquid-interface, allowing the formation of typical histological skin architecture and of a functional barrier (Groeber et 
al., 2016). Decellularized plant tissues have been also used as scaffolds to be colonized by endothelial cells (Gershlak et al., 2017).

To reproduce the peripheral skin nerve system, fibroblasts have been cultured with endothelial cells and dorsal root ganglion neurons in a collagen-chitosan sponge, with or without keratinocytes seeded above (Gingras et al., 2003a). Similarly, to study motor neuron axonal migration and myelination, mouse spinal cord motor neurons are seeded on a collagen sponge populated with Schwann cells and fibroblasts (Gingras et al., 2008). Very recently, neural stem cells, generated through direct reprogramming of dermal fibroblasts, have been incorporated into silk-collagen-based skin equivalents with immune and adipose cells to obtain a neuroimmune-cutaneous system (Lightfoot et al., 2018).

A limitation of these skin equivalents is the limited availability and the low proliferative potential of cultured primary skin cells. Induced pluripotent stem cells (iPSCs) can differentiate into all skin cell types, including sensory neurons and dermal papilla cells (Abaci et al., 2017; van den Broek et al., 2017), and already have been used to generate full-thickness skin equivalents. Thus, they may be a valid source for large scale production of different skin cell types, with enhanced reproducibility.

\subsection{Next generation skin equivalents: towards fully reconstituted and functional skin}

Despite all efforts toward improved skin equivalents, an organotypic model recapitulating the entire complexity of human skin is not yet available. Developing skin equivalents within microfluidic devices represents a step forward for models of growing complexity, and for better mimicking skin function (van den Broek et al., 2017). Microfluidic platforms are an ensemble of controllable chambers and channels in the $\mu \mathrm{m}$ range, combining microsystems and cell biology techniques. Early microfluidic devices were produced using silicone microfabrication and micromachining techniques (Chiu et al., 2001). Less expensive and easier to fabricate devices have been developed by employing the biocompatible silicone rubber poly(dimethyl siloxane) (PDMS) (Whitesides, 2006). Microfluidic platforms allow perfused vascular networks, thus mimicking the in vivo physical force exerted by flowing blood (shear stress), essential for modulating endothelial cell gene expression, morphology, proliferation, and apoptosis (D'Arcangelo et al., 2006, 2016; Song and Munn, 2011). A dynamically perfused chip-based bioreactor chamber able to apply variable mechanical shear stress to skin equivalents was first described in 2013 (Ataç et al., 2013). This platform has been used to culture skin equivalents, skin biopsies, or explants of single hair follicular units. It allows long-term maintenance of composite skin equivalents, and one can perform multiple tests without device disassembly or tissue disruption. Moreover, the tissue can be easily removed from the device for histological processing and further analyses. In general, microfluidic systems, by allowing dynamic perfusion and a finely tuned control of the airflow and gas composition of the air-exposed region, improve epidermal stratification, differentiation, and barrier functions (Sriram et al., 2018).

A microfluidic device has been recently used to generate a fully innervated human skin tissue that recapitulates and replicates skin sensory function in vitro by supplementing skin equivalents with rat dorsal root ganglion (Martorina et al., 2017). However, the current unavailability of human sensory neurons in culture limits the development of a model based on human cells.

Microfluidic devices also are useful to create skin immuno-competent models. To this end, a bi-channel device has been used to culture the keratinocyte cell line HaCaT, as a model of the epidermis barrier, on one side, and a human leukemic monocyte lymphoma cell line (U937), to represent human dendritic cells, on the other side (Ramadan and Ting, 2016). The effects of chemical and physical stimulations, such as ultraviolet irradiation, are assessed in this system by measurement of the trans-epithelial electrical resistance and with a magnetic-bead immune assay integrated into the device. Similarly, to mimic skin inflammation and edema for drug testing, a model based on three microfluidic channels was created (Wufuer et al., 2016). The HaCaT cell line, mimicking the epidermis, dermal fibroblasts, and HUVEC, recreating the endothelial layer, are separated by porous membranes to allow interlayer communication. Skin inflammation and edema are induced by applying pro-inflammatory cytokines on the dermal layer and drug efficacy is evaluated by analyzing epidermal barrier functionality and endothelium permeability.

$3 \mathrm{D}$ bioprinting technology has been employed to further improve skin equivalent complexity. Indeed, this fully automated system permits deposition of several cell types and biomaterials to build a structure similar to native human skin (Ng et al., 2016; Lee and Dai, 2017). By using 3D bioprinting, Abaci and co-workers developed a skin equivalent with perfusable, pre-organized vasculature with both primary and iPSC-derived endothelial cells. Alginate channels were suspended in transwell inserts on which skin equivalents were generated by adding fibroblasts in a collagen matrix, as dermal compartment, and keratinocytes for the epidermal compartment. After the cornification process, the channels were dissolved and the alginate removed to leave a hollow network. Endothelial cells were then added to obtain a vascularized skin equivalent (Abaci et al., 2016). Notably, the same authors developed a pumpless "skin-on-a-chip" model in which the culture medium recirculates by placing the devices on a rocking platform (Abaci et al., 2015). Via 3D bioprinting, Mori and co-workers created a perfusable skin equivalent by inserting HUVEC-coated nylon wires within the dermal compartment. The device is attached to silicone tubes and a peristaltic pump. Beyond skin barrier function, this model displays an efficient percutaneous penetration in the endothelialized tubes following drug application (Mori et al., 2017). Recently, a 3D printed niche matrix has been created, which directly and restrictively guides in vitro epidermal progenitor differentiation into sweat gland morphogenesis (Liu et al., 2016).

3D bioprinting technology may be useful to reconstruct mini-organoids reproducing the organization of skin append- 
age niches. Addition of skin appendages will likely further enhance skin equivalent barrier properties.

Native dermis is composed of multiple fibroblast subpopulations that differ in density, anatomic distribution, and functions. Extracellular matrices also exhibit differences in composition and organization (Sriram et al., 2015). 3D bioprinting technology may be helpful to recapitulate the dermal native composition by combining different fibroblast subpopulations with diverse extracellular matrix components.

Altogether, these achievements pave the way to connect the skin with in vitro models of other tissues to create a "human-ona-chip" system for drug screening. Currently, skin has been connected with organs such as liver, intestine, and kidney (Ataç et al., 2013; Abaci et al., 2017; van den Broek et al., 2017).

\section{In silico models}

In silico-based approaches represent innovative strategies to reduce the use of animal models and to contain expenditure of both research materials and time. Given the extreme complexity of the field, appropriate bioinformatic tools suitable to manage the enormous number of biological variables are still under development. In the last years, increasing effort has been made to set up in silico strategies based on clinical data sets and novel analytical algorithms for use in evidence-based medicine and biomarkers identification for both diagnostic and prognostic purposes (Ozerov et al., 2016; Pinto et al., 2017). Such strategies can also be exploited in drug re-positioning, metabolic pathway analyses (Scafuri et al., 2016; Abbas et al., 2017), or toxicological investigations (Dumont et al., 2015; Kranthi Kumar et al., 2017). In the dermatological field, in silico strategies have been applied to 3-D tissue engineering (Vijayavenkataraman et al., 2017), analysis of drug delivery to the skin (Gajula et al., 2017), and prediction of skin permeability (Rocco et al., 2017).

Several public databases are available that host large clinical datasets on gene and protein expression of healthy or disease-affected individuals. Samples are stratified according to different pathologies; however, most datasets are from the cancer field. Analyzing such large data collections allows researchers to set and test clinical hypotheses directly on hundreds or thousands of human specimens. Therefore, mechanistic hypotheses can be tested and refined in silico before being moved toward more "experimental" stages. New datasets are being uploaded daily, further increasing the number of available samples that can be tested. Thus, the possibility to compare disease conditions, such as stage, with patient gender, age, or survival in silico is becoming more concrete every day. However, efforts should be made to recruit more healthy controls, since there currently is less data from healthy individuals than from affected persons.

In the present review, we give an overview of the application of the most represented databases in dermatological issues.
These databases contain datasets with variable case numbers, ranging from very few to hundreds of cases. Statistical evaluation largely depends on the quality of the reported expression data. In fact, sample quality is routinely evaluated before any further analysis. The actual sample numerosity is also crucial, since larger homogenous experimental datasets better represent the general population. In silico applications for melanoma and skin wound healing are reported in the dedicated paragraphs.

\subsection{Gene Expression Omnibus}

Gene Expression Omnibus - $\mathrm{GEO}^{1}$ is a searchable database comprising datasets (named "GDS" as GEO data set) or series (named "GSE" as GEO series), all referring to published studies. Data can be directly accessed and transferred to statistical packages for evaluation. Data from human biopsies as well as from cultured cell lines, both of human and non-human origin, are available. Several studies have been reported that exploit GEO to address in silico clinical issues, such as identification of genes involved in breast cancer aggressiveness (Guo et al., 2017), key genes in hepatocellular adenoma (Liu et al., 2017a), lung cancer (Liu et al., 2017b), or colorectal cancer (Geng et al., 2017; Wu et al., 2017; Zong et al., 2017). Gene expression data from GEO have been used to validate autoantibody signature in meningioma patients (Gupta et al., 2017a). Relevant upor down-regulation of key genes identified with GEO analyses were used to propose novel prognostic markers in pancreatic ductal adenocarcinoma (Ma et al., 2017), thyroid cancer (Chang et al., 2017), and glioblastoma (Bo et al., 2017). For instance, high levels of interleukin- 6 receptor mRNA have been related to a better prognosis in ovarian cancer patients (Chen et al., 2017). Expression profile data from this database also have been investigated to identify genes involved in rheumatoid arthritis pathogenesis (Zhang et al., 2017a), endometrial function (Young et al., 2017), and Japanese encephalitis virus-infected cells (Gupta et al., 2017b).

GEO has been extensively used to investigate dermatological pathologies. Inkeles and colleagues (2015) analyzed gene expression in 16 different skin-inflammatory, skin-infectious, and skin-neoplastic conditions, such as leprosy or psoriasis, using Affimetrix data from 311 human skin biopsies, and their analysis led to identification of molecular classifiers able to discriminate among different diseases with high accuracy, sensitivity, and specificity. Such an approach opens new ways toward the molecular characterization of skin diseases and represents a relevant diagnostic improvement. Ghosh and colleagues (2015) published a study exploiting GEO to identify genes discriminating between normal skin and atopic dermatitis; 89 genes involved in immune response regulation, keratinocyte differentiation, development, inflammation, and lipid metabolism were detected.

\subsection{Oncomine database}

Oncomine $^{2}$ is a database that allows the analysis of gene expression in cancer versus normal as well as cancer versus can-

\footnotetext{
1 https://www.ncbi.nlm.nih.gov/

2 http://www.oncomine.com
} 
cer samples, either in human biopsies or cultured cells. Investigations in Oncomine have led to published studies since 2007. Long non-coding RNA PVT1 expression has been studied in hepatocellular carcinoma, identifying the DLC1 gene as negatively correlated to PVT1 expression (Zhang et al., 2017b). The melanoma antigen A12 has been investigated in prostate and colorectal cancer cells demonstrating its role as cell cycle regulator via p21 (Yanagi et al., 2017). Other genes such as RAD51, GINS1, TRIP13, and MCM2, involved in DNA-damage control, have been related to a worse outcome in breast cancer (Nieto-Jiménez et al., 2017), while FRG1, a component of the human spliceosome, has been related to tumor progression and tumor angiogenesis (Tiwari et al., 2017). Oncomine analysis was also useful to reveal that cyclin D1 over-expression correlates with poor prognosis in gastric cancer (Shan et al., 2017).

We investigated the expression of 90 ion channel genes in a total of 3673 patients reported in Oncomine (namely, 2999 samples of bladder cancer, glioblastoma, melanoma, breast invasive-ductal cancer, lung carcinoma patients, and 674 controls), demonstrating that their expression was significantly modified in tumor samples and hypothesizing a relationship between such modifications and altered angiogenesis (Biasiotta et al., 2016). In this study, the in silico analysis of publicly available data allowed to test a working hypothesis on thousands of human specimens from different cancer types, an investigation that would not have been possible by following a conventional experimental approach.

\subsection{Other available databases}

The IST online database (http://ist.medisapiens.com/) comprises transcriptomic data and allows interesting correlation plots of the genes of interest in several hundred human specimens, from cancer to healthy tissues.

In the last ten years, the Human Protein Atlas ${ }^{3}$ (HPA) has become available, representing a large collection of protein expression and protein localization data in several healthy and diseased tissues as well as cell lines (Thul and Lindskog, 2018). HPA can be searched for any given protein. Several studies exploited HPA in diverse pathological contexts, such as diabetes (Lindskog et al., 2012), heart (Li et al., 2013) and kidney diseases (Wang et al., 2017a). Skin models and diseases have been investigated with HPA, allowing identification of skin-enriched proteins (Edqvist et al., 2015), proteins distinctive of squamous cell carcinoma (Azimi et al., 2016), or expression of transcription factors in several cancers including skin cancers (Kaufhold et al., 2016).

Besides human databases, a mouse gene expression atlas ${ }^{4}$ is also available. It has been used to evaluate gene expression in Huntington's disease (Mazarei et al., 2010) and to investigate mouse tissue development and functions (Hoffman et al., 2006). This database may be relevant to understand aspects of mouse biology without directly performing experiments in the animal models.

\section{Non-animal models for the study of skin pathophysiology}

\subsection{Immunological diseases}

\subsubsection{Irritant and allergic contact dermatitis}

One of the critical fields in which alternative methods could be of benefit is the detection of adverse drug reactions. For in vitro modelling of irritant dermatitis, where a cosmetic or an allergen is directly toxic to keratinocytes, skin equivalents are already in use. Efforts to replace the in vivo Draize skin irritation test led in 2007 to validation of the reconstructed human epidermis model EpiSkin ${ }^{\mathrm{TM}}$ as the only stand-alone test showing sufficient sensitivity and specificity (Eskes et al., 2007). With the completion of the validation study, performance standards were defined (ECVAM SIVS ${ }^{5}$, May 2007) and then used to evaluate the accuracy and reliability of other analogous systems. For example, the reference test method was used by Alépée et al. (2010) to demonstrate the equivalence of the in vitro SkinEthic ${ }^{\mathrm{TM}}$ RHE skin irritation assay in a formal inter-laboratory study.

Efforts have been made to develop reliable in vitro assays able to distinguish sensitizers from non-sensitizers for the safety evaluation of substances and for eliminating animal studies, such as the guinea pig test or the murine local lymph node assay. The pathway that leads to allergic contact dermatitis is well known: 1) allergen penetrates the skin and can react towards endogenous proteins as it is (hapten), or can be metabolically activated in order to react (pro-hapten); 2) allergen activates a cytoprotective pathway in keratinocytes and, in parallel, keratinocytes elaborate an inflammatory response by secreting pro-inflammatory mediators; 3) pro-inflammatory cytokines, in turn, induce activation, maturation, mobilization, and migration to proximal lymph node of cutaneous Langerhans cells, mature dendritic cells; 4) in the lymph node, these cells present antigen to naïve $\mathrm{T}$ lymphocytes that start proliferating and differentiate into specific T-cells.

Considering the complexity of this pathology, developing alternative methods has proceeded by evaluating the above-described four key events that lead to the adverse outcome pathway (AOP), i.e., inflammation upon challenge with an allergen. Today, the first three key events are assessable by non-animal methods approved by the Organization for Economic Cooperation and Development (OECD). To mimic the first key event, the direct peptide reactivity assay (DPRA), or peptide binding assay, has been developed (OECD TG442C). This is a cell-free assay using artificial model peptides, developed by Gerberick and co-workers in 2004. It is based on the ability of a chemical allergen to react with proteins prior to induction of skin sensitization (Gerberick et al., 2004). Since most chemical allergens are electrophilic, they react with neutrophilic amino acids, such as cysteine or lysine. Test substances are diluted in an appropriate buffer, depending on the amino acid model peptides,

\footnotetext{
3 https://www.proteinatlas.org

4 http://www.mouseatlas.org

5 http://ecvam.jrc.it/index.htm
} 
incubated with the peptides, and free peptides are analyzed by high-pressure liquid chromatography (HPLC). A skin sensitizer molecule will induce depletion of free cysteine and lysine peptides. To address the induction of a cytoprotective pathway in skin keratinocytes, the KeratinoSens ${ }^{\mathrm{TM}}$ assay has been developed (OECD TG442D). It utilizes genetically-modified Ha$\mathrm{CaT}$ carrying a reporter gene for luciferase under the control of an antioxidant-response element, thus monitoring the activity of Nrf2 transcription factor that accumulates in the nucleus of cells following protein modification by sensitizers (Emter et al., 2010; Andreas et al., 2011). The human cell line activation (h-CLAT) test (OECD TG442E) aims at testing the third key event, dendritic cell maturation following exposure to skin sensitizers, evaluating changes in mature dendritic cell biomarker expression. The assay uses the THP-1 monocytic leukemia cell line as a surrogate for human dendritic cells (Ashikaga et al., 2006; Sakaguchi et al., 2006). These cells are exposed to different concentrations of substances under examination and cell viability is assessed through a propidium iodide cytotoxicity assay. Membrane expression of CD54/ICAM-1 and/or CD86/ BT.2 as differentiation markers is then analyzed as final readout. A variant is represented by the U-SENS ${ }^{\mathrm{TM}}$ assay, formerly known as myeloid U937 skin sensitization test (MUSST), that uses U937 cells and measures CD86/BT.2 induction by flow cytometry (Python et al., 2007)(OECD TG442E), and by the IL-8 Luc assay (Kimura et al., 2015)(OECD TG442E), where the effects of chemicals on interleukin (IL)- 8 promoter activity are evaluated by the IL- 8 reporter cell line THP-G8. A validated assay for the forth key event, the immunological response in the draining lymph node, is still lacking. In this field, the human T-cell priming assay (hTCPA) has been proposed (Dietz et al., 2010; Richter et al., 2013). The method uses naïve $\mathrm{T}$ lymphocytes and monocyte-derived dendritic cells exposed to the chemical and evaluates by flow cytometry the frequency of antigen-specific T-cells and production of the cytokines interferon (IFN)- $\gamma$ and tumor necrosis factor (TNF)- $\alpha$. While simple in principle, it is quite complicated from an experimental point of view and not much informative. Additional work is needed to further clarify this aspect (van Vliet, 2017).

It is now clear that, to reach a good predictivity and improve on animal-based methods, different in vitro tests should be performed in sequence and only combinations of methods in integrated approaches to testing and assessment (IATA) will be effective (Bauch et al., 2012; Roberts and Patlewicz, 2018).

\subsubsection{Atopic dermatitis}

Atopic dermatitis is a chronic, eczematous skin disease caused by a disequilibrium in the interaction between immune and skin barrier systems, and resulting in the formation of erythematous plaques, eruption, lichenification accompanied by pruritus, and cutaneous hypersensitivity (Otsuka et al., 2017). Acute skin lesions show T-helper type 2 (Th2) lymphocyte inflammation with CD4+ T-cell and eosinophil infiltration. The subsequent chronic phase shows local Th1 interferon- $\gamma$ responses, augmented numbers of mast cells and dendritic cells, and tissue remodeling with increased collagen deposition.
Moreover, atopic dermatitis manifests changes in the chain length of the lipids of the stratum corneum. Both environmental and genetic factors have been linked to the development of atopic dermatitis. In particular, mutations in the genes encoding filaggrin, the serine peptidase inhibitor Kazal-type 5, and corneodesmosin, which are three components of the epithelial barrier, are associated with atopic dermatitis. Several mouse models for atopic dermatitis have been developed and have contributed to a deeper understanding of disease pathogenesis. They comprise: 1) models induced by epicutaneous application of sensitizers; 2) transgenic mice that over-express or lack selective molecules, including the components of the skin barrier that are mutated in human patients; 3) mice that spontaneously develop atopic dermatitis-like lesions in the skin. These models display many but not all features of the human disease (Kabashima and Nomura, 2017). To give answer to specific molecular questions on the development of atopic dermatitis, skin equivalents have been proven relevant as well, enabling the controlled induction of atopic dermatitis-associated features by the selective addition of proinflammatory cytokines (Kamsteeg et al., 2011). Such models only can be used for the study of epidermal pathologic features and for identification of drugs that act at the epidermal level. In fact, most of the known atopic dermatitis therapeutics that target the immune system are not able to reverse the atopic phenotype of these skin equivalents (Kamsteeg et al., 2011). Danso et al. found that addition of IL-4, IL-13, IL-31, and TNF- $\alpha$ during generation of the skin equivalents induces intercellular edema (spongiosis), altered expression of epidermal differentiation proteins, and secretion of thymic stromal lymphopoietin, which is a master regulator of Th2-driven inflammation by keratinocytes (Danso et al., 2014). Moreover, such a treatment decreases long-chain fatty acid and ceramide levels, thus affecting lipid organization, all hallmarks of atopic dermatitis. More recently, a skin equivalent has been developed with keratinocytes that do not express filaggrin cultured in the presence of the Th2-derived cytokines IL-4 and IL-13 (Hönzke et al., 2016) or of activated CD4+ T-cells (Wallmeyer et al., 2017). These new skin equivalents represent an alternative to animal models for identifying the relative contribution of filaggrin deficiency and inflammation in the development of pathological manifestations of atopic dermatitis.

\subsubsection{Psoriasis}

Psoriasis is a chronic inflammatory disease characterized by erythematous-squamous plaques with epidermal hyperplasia, increased vascularity, and a dermal mixed leukocyte infiltrate (Liang et al., 2017). Both innate and adaptive immune systems are causally involved in disease pathogenesis. To develop a relevant in vitro model of psoriasis, multiple interactions between different cell types, such as epidermal keratinocytes, endothelial cells, neutrophils, and T-lymphocytes, should be considered. So far, such a cell complexity has not been achieved in vitro. Skin equivalents have been produced with keratinocytes and/or fibroblasts derived from psoriatic patients in order to reproduce the cytokine and chemokine expression pattern of 
psoriasis (Barker et al., 2004; Jean et al., 2009), or with keratinocytes treated with transglutaminase inhibitors to induce typical features of psoriatic keratinocytes (hyperproliferation and parakeratosis, i.e., retention of nuclei in the keratinocytes of the horny layer) (Harrison et al., 2007), or in which lymphocytes are included (van den Bogaard et al., 2014). Angiogenesis is another important hallmark of psoriasis. Using the self-assembly methods without any scaffold-like biomaterials, Ayata et al. proposed a skin equivalent composed either of psoriatic fibroblasts and keratinocytes or healthy cells, with the addition of normal skin microvascular endothelial cells (Ayata et al., 2014). In this model, capillary-like structures are more numerous, complex, and branched in the psoriatic substitutes than in the non-psoriatic ones, clearly indicating an effect of psoriatic keratinocytes and fibroblasts on endothelial cells. Although diseased cells have the intrinsic ability to give rise to a psoriatic phenotype, their use is limited by difficulties in obtaining skin biopsies from patients, and by heterogeneity of patient-derived cells. Therefore, a different approach has been used by other authors. Starting from a reconstructed skin model with normal adult keratinocytes, they induced a psoriatic phenotype through addition of pro-inflammatory cytokines ( $\mathrm{Sa}$ et al., 2007; Tjabringa et al., 2008). Depending on the type of cytokines used, these models may be useful to study the psoriasis pathogenesis without the need to incorporate neutrophils or T-lymphocytes into the skin equivalent.

\subsubsection{Cutaneous T-cell lymphomas}

Cutaneous T-cell lymphomas are a heterogeneous group of malignant lympho-proliferative disorders of which the most frequent form is mycosis fungoides (MF) (Dummer et al., 2000). From a primary involvement of the skin with patches and plaques, tumor cells may spread to lymph nodes and visceral sites. In MF, cancer cells have a mature CD4+ T-helper cell phenotype. Despite MF's tumorigenic nature, these cells hardly grow in vitro and cell line establishment is extremely difficult. At the same time, a limited number of animal models is available, as MF cell lines rarely grow when engrafted in nude mice (Charley et al., 1990; Krejsgaard et al., 2010), making the study of pathogenic mechanisms and preclinical analyses of potential novel therapeutic agents challenging. Considering the difficulties of obtaining tumors by subcutaneous inoculation of cancer cells, other routes have been considered. An example is the human MF cell intra-hepatic xenograft in nude mice (Andrique et al., 2016). This approach leads to quick tumor growth, and kidney and lung metastasis. However, no skin infiltration is achieved. Taking into consideration the problems met with animal models, cutaneous T-cell lymphomas represent an interesting research area for non-animal experimental models. By using organotypic systems, Thode et al. (2015) provided insights into the interplay between MF T-cells and skin keratinocytes and into the MF potential in remodeling the skin barrier. In this model, cells from established MF cell lines are added to skin equivalents 24 hours after seeding keratinocytes onto the collagen/fibroblast matrix. Alternatively, devitalized human acellular dermis is used as the supporting framework for 3D cultures (Ridky et al., 2010). Fibroblasts are introduced into the stromal side of the tissue, keratinocytes and MF cells are seeded onto the basement-membrane side, and MF persistence as well as migration in the dermis compartment are monitored. These models have led to some informative results, but no data has been reported so far on the action of therapeutic compounds on embedded MF cells, and the authors are not aware of the establishment of similar models for other, rarer cutaneous T-cell lymphoma forms.

\subsection{Non-animal methods for aging and non-melanoma skin cancers (NMSC)}

\subsubsection{Aging}

Two types of skin aging may be distinguished: intrinsic or chronological aging, and extrinsic or photo-aging. Chronological aging is time-dependent, and it is mainly influenced by genetic factors. Photo-aging depends on UV irradiation. These two aging types are superimposed in sun-exposed skin (Fisher et al., 2002; Kim and Park, 2016). Clinical signs of chronological aging include thinning, wrinkle formation, dryness, loss of elasticity, and fragility (Kim and Park, 2016). Histological manifestations comprise epidermal atrophy associated with reduced numbers of melanocytes, Langerhans cells and fibroblasts in the dermis where collagen fibers are loose, thin, and disorganized (Yaar and Gilchrest, 2007). Epidermal atrophy mainly affects the stratum spinosum and it is a consequence of a lower epidermal turnover rate (Fuchs, 2016). A skin equivalent model displaying epidermal atrophy has been obtained by over-expressing the senescence effector p16 in keratinocytes. We and others have demonstrated that atrophy severity depends on p16 expression levels in the epidermal component of the skin equivalent (Adamus et al., 2014), and can be reverted by down-regulating p16 expression (Maurelli et al., 2006; Adamus et al., 2014). Advanced glycation end products (AGEs), resulting from non-enzymatic glycation of proteins and lipids, accumulate during chronological aging (Ahmed, 2005). In the skin, this reaction creates cross-links between collagen fibers, leading to accumulation of insoluble collagen, loss of elasticity, and wrinkle development (Corstjens et al., 2008). Moreover, AGEs interact with AGE receptors and other receptors on fibroblasts that become activated and release either growth factors or cytokines involved in inflammatory responses or matrix metalloproteinases (MMPs) that remodel the dermal matrix (Okano et al., 2002; Molinari et al., 2008; Pageon, 2010). Taking this into account, skin equivalents have been developed using artificially-glycated collagen. These models closely mimic features of chronologically aged skin, thus strengthening the pathogenic role of glycation in skin aging (Pageon and Asselineau, 2005; Pageon et al., 2015). Additionally, since aged skin is characterized by inflammatory processes, skin equivalents comprising AGE receptor-expressing monocytes have been developed (Pageon et al., 2017).

Acute or repeated sun exposures induce short-term cutaneous damage, such as skin erythema and sunburn, or long-term effects, such as photo-aging or UV-induced skin cancer (Fisher 
et al., 2002; Kim and Park, 2016). UV radiation affects both the epidermis and the dermis, and skin equivalent irradiation with defined UVA or UVB doses is able to simulate acute and chronic sun exposure. Thus, skin equivalents are useful to study cell and extracellular matrix modifications induced by acute and chronic sun exposure, and a reliable system to evaluate sunscreen efficacy (Bernerd and Asselineau, 2008; Bernerd et al., 2012). Twenty-four hours after acute exposure to UVB, sunburnt cells with DNA lesions appear in suprabasal layers (Bernerd and Asselineau, 1997). Superficial fibroblasts undergo apoptosis after a 6-hour acute exposure to UVA, and are eliminated 48 hours later (Bernerd and Asselineau, 1998). UV exposure at a suberythemal dose potently stimulates production and release of fibroblast-derived elastase that is implicated in the early events of photo-aging leading to drastic alterations of dermal structure and to "solar elastosis" (Bernerd et al., 2000; Bernerd and Asselineau, 2008; Imokawa and Ishida, 2015). UV radiation also increases the production of MMP-1, which hydrolyses type I collagen, thus playing a crucial role in the disorganization and progressive degeneration of dermal extracellular matrix. Under UVA exposure, MMP-1 production is directly induced in dermal fibroblasts. On the other hand, UVB radiation stimulates keratinocytes to release soluble factors that induce MMP-1 secretion by a paracrine mechanism (Fagot et al., 2004; Bernerd et al., 2012). UV radiation also contributes to AGE accumulation, likely through induction of an oxidative environment, thus exacerbating alterations caused by chronological aging (Pageon, 2010). A hallmark of photo-aged skin is the presence of senile lentigines, i.e., liver or age spots, that are associated with increased melanogenesis and melanogenic cytokines in the upper dermis. The influence of dermal fibroblasts on skin pigmentation levels has been demonstrated using a functional pigmented reconstructed skin equivalent composed of a melanocyte-containing epidermis. Notably, natural photo-aged fibroblasts contribute to skin hyperpigmentation associated with photo-aging (Duval et al., 2014).

The protective effects of sunscreens against UV-induced damage may be evaluated in skin equivalents. The presence of a horny layer allows topical application of sunscreen formulations on skin equivalent surface, mimicking in vivo conditions (Bernerd et al., 2000, 2012; Bernerd and Asselineau, 2008).

Sunscreens and other cosmetics contain a variety of chemicals able to induce genotoxic stress. Notably, several products are applied daily over a long time, thus cell sensitivity to genotoxic stress increases with age. Human skin equivalents overcome the limits of classical in vitro genotoxicity tests, such as the analysis of DNA-repair competence or of xenobiotic metabolism, due to the fact that those tests are performed on non-human species. Two in vitro genotoxicity tests have been developed using commercially available skin equivalents to investigate DNA damage after topical chemical application. The reconstructed skin micronucleus (RSMN) assay analyzes chromosomal damage by detection of micronuclei in EpiDerm $^{\text {TM }}$ tissues (Curren et al., 2006; Hu et al., 2009; Aardema et al., 2010). The 3D skin comet assay detects both chromosomal damage and DNA lesions in the EpiDerm ${ }^{\mathrm{TM}}$ and in the
Phenion ${ }^{\circledR}$ full-thickness skin model (Reisinger et al., 2018). These assays are able to address different types of DNA damage with high predictivity and good intra- and inter-laboratory reproducibility (Hu et al., 2009; Aardema et al., 2010; Reisinger et al., 2018). Thus, the use of both the RSMN and the 3D skin comet assay is recommended by the Scientific Committee on Consumer Safety (SCCS), an independent expert panel of the European Commission, as follow-up systems to be applied to check suspected misleading results from in vitro standard genotoxicity testing batteries (Reisinger et al., 2018).

\subsubsection{Non-melanoma skin cancers (NMSCs)}

NMSCs are the most frequently diagnosed cancer form in humans (Didona et al., 2018). The majority of NMSCs are basal cell carcinomas (BCC) $(70 \%)$ and squamous-cell carcinomas (SCC) $(25 \%)$ arising from the basal layer and the squamous layers, respectively. BCC rarely metastasize whereas SCC show a variable metastatic rate, a potential for recurrence, and an overall higher risk for human health. BCC cells hardly grow in vitro, and cell line establishment is extremely difficult. Therefore, most studies have been carried out on SCC-derived cell lines (Rheinwald and Beckett, 1981; Patel et al., 2012; Adhikary et al., 2013). Remarkably, these cells cannot always drive tumor formation and recreate the original SCC histological organization when implanted in mice. Monolayer SCC cultures were used to characterize different steps of cancer progression, but they cannot comprise the effects of cancer-associated fibroblasts, which are crucial for the development of an invasive state in vivo. On the contrary, in vitro skin equivalent models allow the study of tumor development dynamics (Obrigkeit et al., 2009; Commandeur et al., 2012; Brauchle et al., 2013). Addition of SCC cell lines onto skin equivalents generates an organotypic model with histological and immunohistochemical similarities to in vivo SCC (Fig. 4C and D). Twenty-four hours after seeding, SCC cells are present in different epidermal layers of the skin equivalent and, in turn, the epidermal compartment displays an altered morphology, resembling SCC in situ. SCC cells can penetrate through the basement membrane into the dermal component. Indeed, clusters of tumor cells may be found in the dermis following 5-8 additional days in culture. However, these skin equivalents do not exhibit either differentiated keratinocytes within invasive cells or the presence of the typical round-shaped foci of hyperkeratosis named "horny pearls" (Obrigkeit et al., 2009; Commandeur et al., 2012).

Recently, two model systems mimicking early and late stage SCC were established. As a model of the pre-invasive stage, SCC cells are co-seeded with keratinocytes onto the fibroblast-containing substrate. The obtained skin equivalent is characterized by encapsulated keratin pearls in the epidermis. As a model of the invasive stage, SCC cells are seeded together with fibroblasts directly into the dermal layer. There, SCC cells form hyper-keratinized tumor cell nests resembling "horny pearls" (Brauchle et al., 2013). These models are excellent tools to study dermal-epidermal interactions in SCC initiation and progression, and are reliable in vitro systems to 
study the effects of therapeutics (Obrigkeit et al., 2009; Commandeur et al., 2012). In fact, to evaluate the biological effects observed in vivo by the combined administration of the two chemotherapeutic drugs gemcitabine and a small inhibitor of Wee1, we used a skin equivalent model and found that modulation of both CDC2 phosphorylation and of a previously-identified gene signature was clearly detectable in human epidermis, suggesting that this system represents a promising tool for identification and validation of novel pharmacodynamic biomarkers (Paolini et al., 2013).

\subsection{Alternative technologies for melanoma studies}

Melanoma has been largely investigated using human and non-human melanoma cell lines, as well as animal models. Human melanoma tissue arrays were used in the early 2000 s (Baldi et al., 2002) to validate molecular mechanisms underlying melanoma development (Kerkar et al., 2016). As an alternative, $3 \mathrm{D}$ models better mimicking the tumor microenvironment have been developed to study melanoma progression and for preclinical drug screening.

\subsubsection{Spheroids}

Cells dissociated from an organ and cultured in a dish under appropriate conditions have the intrinsic ability to reorganize and reform a smaller, simpler version of the originating organ, named organoids or spheroids. In the first innovative study with spheroids, a mini-gut was developed starting from intestinal epithelial stem cells (Sato et al., 2011). Subsequently, spheroids have been grown from stem cells of other epithelial organs (Duarte et al., 2017) and tumors (Fatehullah et al., 2016). Spheroids can be formed directly from tumor-derived cells, from established tumor cell lines, or from single cancer stem cells after clonal expansion (Ishiguro et al., 2017). Spheroids represent a methodology to preserve and store clinical tumor samples (van de Wetering et al., 2015) and have been extensively used to gain insight into tumor growth and metastasis formation (Gao and Chen, 2015) or for drug discovery (Weeber et al., 2017). As spheroids can be derived from a single cell and be ready for drug testing within 2-3 months, they represent a step towards personalized medicine, even if the high amount of cytokines and factors in the culture medium can influence the responses to various compounds (Broutier et al., 2017). Spheroids are likely better representative of early tumors, however they maintain most of the features of the originating cells (Sachs and Clevers, 2014). Melanoma spheroids have been developed by culturing human melanoma cell lines alone or together with stromal cells (Marconi et al., 2018). Melanoma spheroid models have been used to assess several aspects of melanoma biology including growth regulation by cyclin-dependent kinases (LaRue et al., 2004), involvement of laminins in melanoma differentiation (Larson et al., 2014), and melanoma drug screening (Müller and Kulms, 2018; Stevenson et al., 2018).

\subsubsection{Skin equivalent-based models}

Skin equivalents for melanoma studies have been produced by culturing primary and metastatic melanoma cells from es- tablished cell lines plated together with keratinocytes on fibroblast-contracted collagen gels. Interestingly, cells from a radial growth phase melanoma nestle within the epidermis and at the epidermal-dermal junction, whereas cells from a vertical growth phase melanoma or from metastatic melanoma colonize the epidermis and infiltrate deeply into the dermis (Meier et al., 2000). Using both spheroids and melanoma skin equivalent models, Ostyn and colleagues (2014) showed that TNF- $\alpha$ expands the cancer stem cell compartment. To identify the best matrix for melanoma growth, comparisons have been carried out among bovine or rat-tail collagen matrix, human fibroblast-derived matrix, non-cellular de-epidermized dermis, and a fully-cellular de-epidermized dermis with an intact basement membrane. Notably, melanoma cells of non-metastatic origin grow in the dermis of skin equivalents only with fibroblast-derived matrix (Commandeur et al., 2014). Therefore, additional analyses aimed at investigating early melanoma invasion have been carried out with fully humanized skin equivalents in which fibroblasts are stimulated to produce their own extracellular matrix. Melanoma cells are then seeded onto the dermal equivalent prior to the incorporation of human keratinocytes (Hill et al., 2015). Finally, with the aim of recapitulating metastasis formation, the two above described techniques were merged: melanoma spheroids were prepared and then settled into the dermal fibroblast/collagen scaffold of the skin equivalent prior to the addition of keratinocytes and their differentiation (Vörsmann et al., 2013).

\subsubsection{In silico models}

Different melanoma studies have been carried out by exploiting in silico investigations with the above-mentioned databases. Wang et al. (2017b) identified long non-coding RNAs differentially expressed in melanoma biopsies compared to normal skin in GEO. GEO gene expression data were analyzed to investigate specific molecular immunoglobulin pathways (Saul et al., 2016) as well as vascular endothelial growth factor (VEGF)-A and melanogenesis associated transcription factor (MITF) expression (Puujalka et al., 2016) in human melanoma. According to data reported in four different GEO datasets (namely GDS1375, GDS1989, GDS2200, GDS1965) referring to 94 patients, we evaluated the expression of different isoforms of platelet-derived growth factor receptors (PDGF-R) in human biopsies from melanoma versus nevi, demonstrating that PDGFR- $\alpha$ is strongly reduced in melanoma samples (Faraone et al., 2009). Such data suggested a possible onco-suppression function of PDGFR- $\alpha$ in melanoma pathogenesis and represented a preliminary indication for future experimental studies on the over-expression of PDGFR- $\alpha$ to inhibit melanoma proliferation. Other studies have confirmed the in silico data, further addressing the mechanisms underlying PDGFR- $\alpha$ anti-tumor activity (D'Arcangelo et al., 2016). Using the IST online database we demonstrated that expression of PDGFR- $\alpha$ is almost completely lost in 208 melanomas as compared to 147 normal skin biopsies, and experimental data showed that PDGFR- $\alpha$ acts as a potential onco-suppressor gene negatively selected in melanoma (D'Arcangelo et al., 2016). Integration of expres- 
sion data from the NCI-60 panel of cell lines available in GEO with expression data in human patients available in HPA, has led to the clarification of oxygen consumption and other metabolic strategies in melanoma (Aurich et al., 2017). Using the Oncomine database, a negative correlation has been found that indicates the possibility to use Annexin V as a novel angiogenesis inhibitor in melanoma (Zhang et al., 2017c). Moreover, in silico analysis carried out using Oncomine has been used to validate skin cancer proteomic data (Azimi et al., 2016).

\subsection{Non-animal methods in wound healing}

Cutaneous wound healing is a complex process aimed at the restoration of skin integrity and function following injury. It has been conventionally divided into sequential and partly overlapping phases: hemostasis, inflammation, cell proliferation, and tissue remodeling. All resident cell types, as well as cell populations recruited via the blood stream, take active part in this process (Eming et al., 2014). At present, such a complexity cannot be recapitulated in vitro, and different animal models are used to investigate cellular and molecular events taking part in physiological or altered wound healing, as well as for testing therapeutic approaches (see chapter on animal models). However, a continuous effort has been made to develop alternative methods for wound healing to partly replace animals for these studies.

\subsubsection{Two-dimensional models}

The simplest in vitro method to investigate cell behavior and molecular signaling following injury is by mechanically inflicting a wound in confluent monolayers of a single cell type. Cell migration can be analyzed by monitoring cell gap closure by time-lapse microscopy; molecular events also can be investigated. Diverse approaches are used to interrupt cell monolayers. The scratch assay is performed using pipette tips (Liang et al., 2007), toothpicks (Klettner et al., 2014), special cell scraper scratching devices (Doyle et al., 2012; Zhang et al., 2013a), or metallic micro-indenters (Topman et al., 2012). Modifications of these methods have been developed to obtain automation for high throughput studies (Yue et al., 2010; Liu et al., 2014; Brönneke et al., 2015). Another possible way to mechanically remove cells is by destroying them with a stamp that has the advantage of not removing the matrix coating, which is often damaged by scratches. For most stamping assays, a mold made of rubber (Lan et al., 2010) or polymers (Lee et al., 2010) is used. Other methods employ temperature-controlled stamps (Hettler et al., 2013). Cell layer wounding also can be obtained with electrical (pulses of high voltage current) or optical (laser beam) devices; both methods allow better reproducibility and high throughput processing (Stamm et al., 2016).

Keratinocytes, fibroblasts, and endothelial cells have singularly been analyzed in two-dimensional assays. Despite being useful for investigating some aspects of the wound healing process, confluent cell monolayers do not reproduce the in vivo situation, particularly dermal fibroblasts that are normally embedded in the extracellular matrix with few direct cell-cell contacts. As for keratinocytes, lack of differentiation and barrier formation can limit the information obtained from two-dimensional assays. An in vitro assay better recapitulating the re-epithelialization process with barrier function restoration was set up on corneal stratified epithelial cells in which wounds were inflicted with a metal circular punch (Gonzalez-Andrades et al., 2016). Lack of epithelial-mesenchymal crosstalk is another major limit of 2D in vitro wound models.

\subsubsection{Three-dimensional assays}

Three-dimensional wound healing models have been developed to better mimic in vivo cell-cell and cell-matrix interactions. Different types of skin equivalents containing fully differentiated epidermis and fibroblasts embedded within a matrix have been used (Egles et al., 2010). A wound is inflicted with a scalpel, a punch, or a thermal device, or following laser irradiation, and it involves either the epidermis only or the skin equivalent in its full thickness. Epithelial closure can be monitored over time, and cellular and molecular events occurring during the healing process are analyzed on tissue sections or on protein and RNA extracts (Breetveld et al., 2006; Safferling et al., 2013; Marquardt et al., 2015). To overcome the limitation of obtaining donor skin biopsies, skin equivalents containing TERT-immortalized fibroblasts and keratinocytes have been developed and tested for wound healing responses (Reijnders et al., 2015). Besides recapitulating skin features like primary cell-derived skin equivalents, they can also re-epithelialize and secrete wound-healing inflammatory mediators. As a further development for analysis of altered wound healing mechanisms, skin equivalents assembled with cells isolated from fibrotic scars or keloids, or from the skin of individuals with chronic ulcers could be theoretically employed. They already have been set up with keloid cells and used in wound healing studies after grafting onto nude mice (Lee et al., 2016).

Analysis of the mechanisms underlying wound healing and of drug effects is limited in conventional skin equivalents due to the lack of cell populations playing pivotal roles in skin repair, such as endothelial cells for vessel formation, immune cell types, adipocytes, hematopoietic and endothelial precursors cells, and nerve endings. Attempts have been made to include at least endothelial cells forming capillary-like tubes and activate an angiogenic response following skin equivalent injury (Herman and Leung, 2009). Hair follicles, containing epidermal and mesenchymal precursors have been cultured in skin equivalents to study their contribution to wound healing, particularly for re-epithelialization (Ojeh et al., 2017). A skin model composed of an injured epidermis and a dermis innervated with sensory neurons also has been established to study the re-epithelialization process (Gingras et al., 2003b, 2008; Blais et al., 2009, 2014).

Alternative 3D methods to evaluate novel therapies to promote healing include the use of human skin biopsies taken from abdominal or breast reduction surgery, which are cut into pieces, cultured within matrices with the epithelium at the air-liquid interface, and wounded (Heilborn et al., 2003; Mendoza-Garcia et al., 2015). This ex vivo wound healing model has the advantage of maintaining skin characteristics, 
with keratinocyte proliferation and dermal matrix deposition after wounding. However, cell apoptosis and loss of tissue architecture occur starting from 7 days of culture, which does not allow long-term wound healing analyses (Xu et al., 2012; Mendoza-Garcia et al., 2015).

\subsubsection{Microfluidic models}

Microfluidic models represent a further step towards recapitulating a wound environment more closely resembling the in vivo situation. Soluble factors, gradients, gas concentration, fluid flow, extracellular matrix composition, mechanical properties, and geometry are some of the parameters which microfluidic technology allows to control more finely (Meyvantsson and Beebe, 2008). A lab-on-a-chip system capable of mechanically inducing circular cell-free areas within confluent cell layers in a microfluidic environment has been developed to allow automated, miniaturized and integrated induction of defined wounds (Sticker et al., 2017). Aspects investigated by using microfluidic devices include the control of biofilm infection for chronic wounds (Terry and Neethirajan, 2014), a quantitative investigation of cell migration and proliferation (Zhang et al., 2013b), vascular smooth muscle cell migration (Wei et al., 2015), cell-cell and cell-extracellular matrix interactions (An et al., 2015), endothelial cell migration or sprouting in the presence of growth factor gradients, and shear stress (van der Meer et al., 2010; Verbridge et al., 2013).

\subsubsection{In silico models}

In silico models have been used to reconstruct wound healing mechanisms and to predict the effect of therapeutic approaches. Many different aspects of skin repair have been analyzed by using mathematical models, including the activity of growth factors (Sun et al., 2009), re-epithelialization (Safferling et al., 2013), and angiogenesis (Schugart et al., 2008; Flegg et al., 2012). Collagen bundle distribution, orientation and its effect in wound contraction has been analyzed (Koppenol et al., 2017), as well as impaired healing in hypoxic wounds with varying levels of contamination, the effect of fibroblast death and recruitment rate (Menke et al., 2010), the construction of biomaterials able to support stem cell infiltration and differentiation (Tartarini and Mele, 2015), or the application of hyperbaric therapy to chronic wounds (Flegg et al., 2012). Moreover, agents most involved in skin fibrosis following injury or in delayed healing of diabetic foot ulcers and targets to counteract these pathological conditions have been identified (Mi et al., 2007; Nagaraja et al., 2017).

\section{Conclusions}

The numbers of studies directly referring to non-animal methods were 212 in 1997, 628 in 2007, and 1219 in 2017, according to a PubMed search for "alternative to animal model" in ALL fields, reflecting the large and increasing interest in alternatives to animal studies. Alternative methods for dermatological research include different models, from 2D and 3D culture systems to in silico techniques. At present, the most promising tool is certainly represented by the skin equivalent approach that has evolved from systems containing only keratinocytes seeded on a matrix to more complex cell and matrix aggregates. 3D bioprinting and microfluidic devices represent an improvement towards reproducing the skin's structural, functional, and molecular network properties. The respective models more accurately reconstitute skin architecture and mimic blood flow effects. Further development of in vitro skin systems is a key component of the challenging task of obtaining more accurate knowledge of the biological systems and properly addressing issues of cost, time, and ethics. Ideally, future alternative technologies will be able to reproduce skin within an artificial body context, thus being able to recapitulate some of the interactions with other organs. A lot of work must be done but it will be highly rewarding.

\section{References}

Aardema, M. J., Barnett, B. C., Khambatta, Z. et al. (2010). International prevalidation studies of the EpiDerm 3D human reconstructed skin micronucleus (RSMN) assay: Transferability and reproducibility. Mutat Res 701, 123-231. doi:10.1016/j.mrgentox.2010.05.017

Abaci, H. E., Gledhill, K., Guo, Z. et al. (2015). Pumpless microfluidic platform for drug testing on human skin equivalents. Lab Chip 15, 882-888. doi:10.1039/C4LC00999A

Abaci, H. E., Guo, Z., Coffman, A. et al. (2016). Human skin constructs with spatially controlled vasculature using primary and iPSC-derived endothelial cells. Adv Healthc Mater 5, 1800-1807. doi:10.1002/adhm.201500936

Abaci, H., Guo, Z., Doucet, Y. et al. (2017). Next generation human skin constructs as advanced tools for drug development. Exp Biol Med 242, 1657-1668. doi:10.1177/ 1535370217712690

Abbas, Q., Raza, H., Hassan, M. et al. (2017). Acetazolamide inhibits the level of tyrosinase and melanin: An enzyme kinetic, in vitro, in vivo, and in silico studies. Chem Biodivers 14, e1700117. doi:10.1002/cbdv.201700117

Adamus, J., Aho, S., Meldrum, H. et al. (2014). p16INK4A influences the aging phenotype in the living skin equivalent. J Invest Dermatol 134, 1131-1133. doi:10.1038/jid.2013.468

Adhikary, G., Grun, D., Kerr, C. et al. (2013). Identification of a population of epidermal squamous cell carcinoma cells with enhanced potential for tumor formation. PLoS One 8, e84324. doi:10.1371/journal.pone.0084324

Ahmed, N. (2005). Advanced glycation endproducts - Role in pathology of diabetic complications. Diabetes Res Clin Pract 67, 3-21. doi:10.1016/j.diabres.2004.09.004

Alépée, N., Tornier, C., Robert, C. et al. (2010). A catch-up validation study on reconstructed human epidermis (SkinEthic ${ }^{\mathrm{TM}}$ RHE) for full replacement of the Draize skin irritation test. Toxicol In Vitro 24, 257-266. doi:10.1016/j.tiv.2009.08.024

An, Y., Ma, C., Tian, C. et al. (2015). On-chip assay of the effect of topographical microenvironment on cell growth and cellcell interactions during wound healing. Biomicrofluidics 9, 64112. doi:10.1063/1.4936927

Andreas, N., Caroline, B., Leslie, F. et al. (2011). The intra- and 
inter-laboratory reproducibility and predictivity of the KeratinoSens assay to predict skin sensitizers in vitro: Results of a ring-study in five laboratories. Toxicol In Vitro 25, 733-744. doi:10.1016/j.tiv.2010.12.014

Andrique, L., Poglio, S., Prochazkova-Carlotti, M. et al. (2016). Intrahepatic xenograft of cutaneous T-cell lymphoma cell lines. Am J Pathol 186, 1775-1785. doi:10.1016/j.ajpath. 2016.03.012

Ashikaga, T., Yoshida, Y., Hirota, M. et al. (2006). Development of an in vitro skin sensitization test using human cell lines: The human Cell Line Activation Test (h-CLAT). Toxicol In Vitro 20, 767-773. doi:10.1016/j.tiv.2005.10.012

Asselineau, D. and Prunieras, M. (1984). Reconstruction of 'simplified' skin: Control of fabrication. Br J Dermatol 111 Suppl 27, 219-222.

Ataç, B., Wagner, I., Horland, R. et al. (2013). Skin and hair on-a-chip: In vitro skin models versus ex vivo tissue maintenance with dynamic perfusion. Lab Chip 13, 3555. doi:10.1039/c3lc50227a

Aurich, M. K., Fleming, R. M. T. and Thiele, I. (2017). A systems approach reveals distinct metabolic strategies among the NCI-60 cancer cell lines. PLoS Comput Biol 13, e1005698. doi:10.1371/journal.pcbi.1005698

Avci, P., Sadasivam, M., Gupta, A. et al. (2013). Animal models of skin disease for drug discovery. Expert Opin Drug Discov 8, 331-355. doi:10.1517/17460441.2013.761202

Ayata, R. E., Bouhout, S., Auger, M. and Pouliot, R. (2014). Study of in vitro capillary-like structures in psoriatic skin substitutes. Biores Open Access 3, 197-205. doi:10.1089/ biores.2014.0022

Azimi, A., Kaufman, K. L., Ali, M. et al. (2016). In silico analysis validates proteomic findings of formalin-fixed paraffin embedded cutaneous squamous cell carcinoma tissue. Cancer Genomics Proteomics 13, 453-465.

Baldi, A., Luca, A. De, Morini, M. et al. (2002). The HtrA1 serine protease is down-regulated during human melanoma progression and represses growth of metastatic melanoma cells. Oncogene 21, 6684-6688. doi:10.1038/sj.onc.1205911

Barker, C. L., McHale, M. T., Gillies, A. K. et al. (2004). The development and characterization of an in vitro model of psoriasis. J Invest Dermatol 123, 892-901. doi:10.1111/j.0022202X.2004.23435.x

Bauch, C., Kolle, S. N., Ramirez, T. et al. (2012). Putting the parts together: Combining in vitro methods to test for skin sensitizing potentials. Regul Toxicol Pharmacol 63, 489-504. doi:10.1016/j.yrtph.2012.05.013

Bauwens, C., Yin, T., Dang, S. et al. (2005). Development of a perfusion fed bioreactor for embryonic stem cell-derived cardiomyocyte generation: Oxygen-mediated enhancement of cardiomyocyte output. Biotechnol Bioeng 90, 452-461. doi:10.1002/bit.20445

Bellas, E., Seiberg, M., Garlick, J. and Kaplan, D. L (2012). In vitro $3 \mathrm{D}$ full-thickness skin-equivalent tissue model using silk and collagen biomaterials. Macromol Biosci 12, 16271636. doi:10.1002/mabi.201200262

Bergman, P., Seyedoleslami Esfahani, S. and Engström, Y. (2017). Drosophila as a model for human diseases - Focus on innate immunity in barrier epithelia. Curr Top Dev Biol 121, 29-81. doi:10.1016/bs.ctdb.2016.07.002

Bernerd, F. and Asselineau, D. (1997). Successive alteration and recovery of epidermal differentiation and morphogenesis after specific UVB-damages in skin reconstructedin vitro. Dev Biol 183, 123-138. doi:10.1006/dbio.1996.8465

Bernerd, F. and Asselineau, D. (1998). UVA exposure of human skin reconstructed in vitro induces apoptosis of dermal fibroblasts: Subsequent connective tissue repair and implications in photoaging. Cell Death Differ 5, 792-802. doi:10.1038/ sj.cdd.4400413

Bernerd, F., Vioux, C. and Asselineau, D. (2000). Evaluation of the protective effect of sunscreens on in vitro reconstructed human skin exposed to UVB or UVA irradiation. Photochem Photobiol 71, 314-320. doi:10.1562/0031-8655(2000)071<0 314:EOTPEO>2.0.CO;2

Bernerd, F. and Asselineau, D. (2008). An organotypic model of skin to study photodamage and photoprotection in vitro. J Am Acad Dermatol 58, Suppl 2, S155-159. doi:10.1016/j. jaad.2007.08.050

Bernerd, F., Marionnet, C. and Duval, C. (2012). Solar ultraviolet radiation induces biological alterations in human skin in vitro: Relevance of a well-balanced UVA/UVB protection. Indian J Dermatol Venereol Leprol 78, Suppl 1, S15-23. doi:10.4103/0378-6323.97351

Berthod, F., Germain, L., Tremblay, N. et al. (2006). Extracellular matrix deposition by fibroblasts is necessary to promote capillary-like tube formation in vitro. J Cell Physiol 207, 491-498. doi:10.1002/jcp.20584

Biasiotta, A., D’Arcangelo, D., Passarelli, F. et al. (2016). Ion channels expression and function are strongly modified in solid tumors and vascular malformations. J Transl Med 14, 285. doi:10.1186/s12967-016-1038-y

Black, A. F., Berthod, F., L'heureux, N. et al. (1998). In vitro reconstruction of a human capillary-like network in a tissue-engineered skin equivalent. FASEB J 12, 1331-1340.

Blais, M., Grenier, M. and Berthod, F. (2009). Improvement of nerve regeneration in tissue-engineered skin enriched with schwann cells. J Invest Dermatol 129, 2895-2900. doi:10.1038/jid.2009.159

Blais, M., Mottier, L., Germain, M.-A. et al. (2014). Sensory neurons accelerate skin reepithelialization via substance $\mathrm{P}$ in an innervated tissue-engineered wound healing model. Tissue Eng Part A 20, 2180-2188. doi:10.1089/ten.tea.2013.0535

Bo, L., Wei, B., Li, C. et al. (2017). Identification of potential key genes associated with glioblastoma based on the gene expression profile. Oncol Lett 14, 2045-2052. doi:10.3892/ ol.2017.6460

Boelsma, E., Gibbs, S., Faller, C. and Ponec, M. (2000). Characterization and comparison of reconstructed skin models: Morphological and immunohistochemical evaluation. Acta Derm Venereol 80, 82-88.

Bohnekamp, J., Cryderman, D. E., Paululat, A. et al. (2015). A Drosophila model of epidermolysis bullosa simplex. J Invest Dermatol 135, 2031-2039. doi:10.1038/jid.2015.129

Bondanza, S., Bellini, M., Roversi, G. et al. (2007). Piebald trait: Implication of kit mutation on in vitro melanocyte survival and 
on the clinical application of cultured epidermal autografts. $J$ Invest Dermatol 127, 676-686. doi:10.1038/sj.jid.5700639

Böttcher-Haberzeth, S., Biedermann, T. and Reichmann, E. (2010). Tissue engineering of skin. Burns 36, 450-460. doi:10. 1016/j.burns.2009.08.016

Bourneuf, E. (2017). The MeLiM Minipig: An original spontaneous model to explore cutaneous melanoma genetic basis. Front Genet 8, 146. doi:10.3389/fgene.2017.00146

Bouwstra, J. A. and Ponec, M. (2006). The skin barrier in healthy and diseased state. Biochim Biophys Acta 1758, 20802095. doi:10.1016/j.bbamem.2006.06.021

Brauchle, E., Johannsen, H., Nolan, S. et al. (2013). Design and analysis of a squamous cell carcinoma in vitro model system. Biomaterials 34,7401-7407. doi:10.1016/j.biomaterials.2013. 06.016

Breetveld, M., Richters, C. D., Rustemeyer, T. et al. (2006). Comparison of wound closure after burn and cold injury in human skin equivalents. J Invest Dermatol 126, 1918-1921. doi:10.1038/sj.jid.5700330

Brohem, C. A., da Silva Cardeal, L. B., Tiago, M. et al. (2011). Artificial skin in perspective: Concepts and applications. Pigment Cell Melanoma Res 24, 35-50. doi:10.1111/j.1755148X.2010.00786.x

Brönneke, S., Brückner, B., Söhle, J. et al. (2015). Genome-wide expression analysis of wounded skin reveals novel genes involved in angiogenesis. Angiogenesis 18, 361-371. doi:10.1007/s10456-015-9472-7

Broutier, L., Mastrogiovanni, G., Verstegen, M. M. et al. (2017). Human primary liver cancer-derived organoid cultures for disease modeling and drug screening. Nat Med 23, 1424-1435. doi:10.1038/nm.4438

Campitiello, E., Della Corte, A., Fattopace, A. et al. (2005). The use of artificial dermis in the treatment of chronic and acute wounds: Regeneration of dermis and wound healing. Acta Biomed 76, Suppl 1, 69-71.

Candi, E., Schmidt, R. and Melino, G. (2005). The cornified envelope: A model of cell death in the skin. Nat Rev Mol Cell Biol 6, 328-340. doi:10.1038/nrm1619

Caravaggi, C., De Giglio, R., Pritelli, C. et al. (2003). HYAFF 11-based autologous dermal and epidermal grafts in the treatment of noninfected diabetic plantar and dorsal foot ulcers: A prospective, multicenter, controlled, randomized clinical trial. Diabetes Care 26, 2853-2859.

Casale, C., Imparato, G., Urciuolo, F. and Netti, P. A. (2016). Endogenous human skin equivalent promotes in vitro morphogenesis of follicle-like structures. Biomaterials 101, 8695. doi:10.1016/j.biomaterials.2016.05.047

Chang, Z., Cai, C., Han, D. et al. (2017). Anoctamin5 regulates cell migration and invasion in thyroid cancer. Int J Oncol 51, 1311-1319. doi:10.3892/ijo.2017.4113

Charley, M. R., Tharp, M., Locker, J. et al. (1990). Establishment of a human cutaneous T-cell lymphoma in C.B-17 SCID mice. J Invest Dermatol 94, 381-384.

Chen, J. and Roop, D. R. (2008). Genetically engineered mouse models for skin research: Taking the next step. J Dermatol Sci 52, 1-12. doi:10.1016/j.jdermsci.2008.03.012
Chen, Q., Xu, B., Lan, L. et al. (2017). High mRNA expression level of IL-6R was associated with better prognosis for patients with ovarian cancer: A pooled meta-analysis. Sci Rep 7, 8769. doi:10.1038/s41598-017-09333-8

Chiu, D. T., Pezzoli, E., Wu, H. et al. (2001). Using three-dimensional microfluidic networks for solving computationally hard problems. Proc Natl Acad Sci U S A 98, 2961-2966. doi:10.1073/pnas.061014198

Choi, T.-Y., Kim, J.-H., Ko, D. H. et al. (2007). Zebrafish as a new model for phenotype-based screening of melanogenic regulatory compounds. Pigment Cell Res 20, 120-127. doi:10.1111/j.1600-0749.2007.00365.x

Commandeur, S., van Drongelen, V., de Gruijl, F. R. and El Ghalbzouri, A. (2012). Epidermal growth factor receptor activation and inhibition in $3 \mathrm{D}$ in vitro models of normal skin and human cutaneous squamous cell carcinoma. Cancer Sci 103, 2120-2126. doi:10.1111/cas.12026

Commandeur, S., Sparks, S. J., Chan, H.-L. et al. (2014). In-vitro melanoma models: Invasive growth is determined by dermal matrix and basement membrane. Melanoma Res 24, 305-314. doi:10.1097/CMR.0000000000000079

Corstjens, H., Dicanio, D., Muizzuddin, N. et al. (2008). Glycation associated skin autofluorescence and skin elasticity are related to chronological age and body mass index of healthy subjects. Exp Gerontol 43, 663-667. doi:10.1016/j. exger.2008.01.012

Cuono, C., Langdon, R. and McGuire, J. (1986). Use of cultured epidermal autografts and dermal allografts as skin replacement after burn injury. Lancet 1, 1123-1124.

Curren, R. D., Mun, G. C., Gibson, D. P. and Aardema, M. J. (2006). Development of a method for assessing micronucleus induction in a 3D human skin model (EpiDerm). Mutat Res 607, 192-204. doi:10.1016/j.mrgentox.2006.04.016

D’Arcangelo, D., Ambrosino, V., Giannuzzo, M. et al. (2006). Axl receptor activation mediates laminar shear stress anti-apoptotic effects in human endothelial cells. Cardiovasc Res 71, 754-763. doi:10.1016/j.cardiores.2006.06.002

D’Arcangelo, D., Facchiano, F., Nassa, G. et al. (2016). PDGFR-alpha inhibits melanoma growth via CXCL10/IP10: A multi-omics approach. Oncotarget 7, 77257-77275. doi:10.18632/oncotarget.12629

Danso, M. O., van Drongelen, V., Mulder, A. et al. (2014). TNF- $\alpha$ and Th 2 cytokines induce atopic dermatitis-like features on epidermal differentiation proteins and stratum corneum lipids in human skin equivalents. $J$ Invest Dermatol 134, 1941-1950. doi:10.1038/jid.2014.83

Dellambra, E. and Dimri, G. P. (2009). Cellular senescence and skin aging. In N. Dayan (ed.), Skin Aging Handbook (129148). Elsevier. doi:10.1016/B978-0-8155-1584-5.50011-9

Delort, L., Lequeux, C., Dubois, V. et al. (2013). Reciprocal interactions between breast tumor and its adipose microenvironment based on a 3D adipose equivalent model. PLoS One 8, e66284. doi:10.1371/journal.pone.0066284

Didona, D., Paolino, G., Bottoni, U. and Cantisani, C. (2018). Non melanoma skin cancer pathogenesis overview. Biomedicines 6, 6. doi:10.3390/biomedicines6010006 
Dietz, L., Esser, P. R., Schmucker, S. S. et al. (2010). Tracking human contact allergens: From mass spectrometric identification of peptide-bound reactive small chemicals to chemical-specific naive human T-cell priming. Toxicol Sci 117, 336-347. doi:10.1093/toxsci/kfq209

Doyle, W., Shide, E., Thapa, S. and Chandrasekaran, V. (2012). The effects of energy beverages on cultured cells. Food Chem Toxicol 50, 3759-3768. doi:10.1016/j.fct.2012.07.008

Duarte, A. A., Gogola, E., Sachs, N. et al. (2017). BRCA-deficient mouse mammary tumor organoids to study cancerdrug resistance. Nat Methods 15, 134-140. doi:10.1038/nmeth. 4535

Dummer, R., Hess-Schmid, M. and Burg, G. (2000). Cutaneous T-cell lymphomas: Prognosis and quality-of-life issues. Clin Lymphoma 1, Suppl 1, S21-25.

Dumont, C., Prieto, P., Asturiol, D. and Worth, A. (2015). Review of the availability of in vitro and in silico methods for assessing dermal bioavailability. Appl In Vitro Toxicol 1, 147164. doi:10.1089/aivt.2015.0003

Duval, C., Régnier, M. and Schmidt, R. (2001). Distinct melanogenic response of human melanocytes in mono-culture, in co-culture with keratinocytes and in reconstructed epidermis, to UV exposure. Pigment Cell Res 14, 348-355.

Duval, C., Cohen, C., Chagnoleau, C. et al. (2014). Key regulatory role of dermal fibroblasts in pigmentation as demonstrated using a reconstructed skin model: Impact of photo-aging. PLoS One 9, e114182. doi:10.1371/journal.pone.0114182

Edqvist, P.-H., Fagerberg, L., Hallström, B. M. et al. (2015). Expression of human skin-specific genes defined by transcriptomics and antibody-based profiling. J Histochem Cytochem 63, 129-141. doi:10.1369/0022155414562646

Egles, C., Garlick, J. A. and Shamis, Y. (2010). Three-dimensional human tissue models of wounded skin. Methods $\mathrm{Mol}$ Biol 585, 345-359. doi:10.1007/978-1-60761-380-0 24

el-Ghalbzouri, A., Gibbs, S., Lamme, E. et al. (2002). Effect of fibroblasts on epidermal regeneration. Br J Dermatol 147 , 230-243.

Eming, S. A., Martin, P. and Tomic-Canic, M. (2014). Wound repair and regeneration: Mechanisms, signaling, and translation. Sci Transl Med 6, 265sr6. doi:10.1126/ scitranslmed.3009337

Emter, R., Ellis, G. and Natsch, A. (2010). Performance of a novel keratinocyte-based reporter cell line to screen skin sensitizers in vitro. Toxicol Appl Pharmacol 245, 281-290. doi:10.1016/j.taap.2010.03.009

Eskes, C., Cole, T., Hoffmann, S. et al. (2007). The ECVAM international validation study on in vitro tests for acute skin irritation: Selection of test chemicals. Altern Lab Anim 35, 603-619.

Facy, V., Flouret, V., Régnier, M. and Schmidt, R. (2005). Reactivity of Langerhans cells in human reconstructed epidermis to known allergens and UV radiation. Toxicol In Vitro 19, 787-795. doi:10.1016/j.tiv.2005.03.018

Fagot, D., Asselineau, D. and Bernerd, F. (2004). Matrix metalloproteinase-1 production observed after solar-simulated radiation exposure is assumed by dermal fibroblasts but involves a paracrine activation through epidermal keratinocytes. Photochem Photobiol 79, 499-505.

Faraone, D., Aguzzi, M. S., Toietta, G. et al. (2009). Platelet-derived growth factor-receptor $\alpha$ strongly inhibits melanoma growth in vitro and in vivo. Neoplasia 11, 732-742. doi:10.1593/neo.09408

Fatehullah, A., Tan, S. H. and Barker, N. (2016). Organoids as an in vitro model of human development and disease. Nat Cell Biol 18, 246-254. doi:10.1038/ncb3312

Fisher, G. J., Kang, S., Varani, J. et al. (2002). Mechanisms of photoaging and chronological skin aging. Arch Dermatol 138, 1462-1470.

Flegg, J. A., Byrne, H. M., Flegg, M. B. and McElwain, D. L. (2012). Wound healing angiogenesis: The clinical implications of a simple mathematical model. J Theor Biol 300, 309316. doi:10.1016/j.jtbi.2012.01.043

Fuchs, E. (2016). Epithelial skin biology. Curr Top Dev Biol 116, 357-374. doi:10.1016/bs.ctdb.2015.11.033

Gajula, K., Gupta, R., Sridhar, D. B. and Rai, B. (2017). Insilico skin model: A multiscale simulation study of drug transport. J Chem Inf Model 57, 2027-2034. doi:10.1021/acs. jcim. 7 b00224

Gallico, G. G., $3^{\text {rd }}$, O’Connor, N. E., Compton, C. C. et al. (1984). Permanent coverage of large burn wounds with autologous cultured human epithelium. $N$ Engl J Med 311, 448-451. doi:10.1056/NEJM198408163110706

Gallico, G. G., $3^{\text {rd }}$ and O'Connor, N. E. (1985). Cultured epithelium as a skin substitute. Clin Plast Surg 12, 149-157.

Gao, D. and Chen, Y. (2015). Organoid development in cancer genome discovery. Curr Opin Genet Dev 30, 42-48. doi:10.1016/j.gde.2015.02.007

Garcia, M., Escamez, M. J., Carretero, M. et al. (2007). Modeling normal and pathological processes through skin tissue engineering. Mol Carcinog 46, 741-745. doi:10.1002/mc.20327

Geng, R., Tan, X., Wu, J. et al. (2017). RNF183 promotes proliferation and metastasis of colorectal cancer cells via activation of NF-кB-IL-8 axis. Cell Death Dis 8, e2994. doi:10.1038/cddis.2017.400

Gerberick, G. F., Vassallo, J. D., Bailey, R. E. et al. (2004). Development of a peptide reactivity assay for screening contact allergens. Toxicol Sci 81, 332-343. doi:10.1093/toxsci/kfh213

Gershlak, J. R., Hernandez, S., Fontana, G. et al. (2017). Crossing kingdoms: Using decellularized plants as perfusable tissue engineering scaffolds. Biomaterials 125, 13-22. doi:10.1016/j.biomaterials.2017.02.011

Ghosh, D., Ding, L., Sivaprasad, U. et al. (2015). Multiple transcriptome data analysis reveals biologically relevant atopic dermatitis signature genes and pathways. PLoS One 10, e0144316. doi:10.1371/journal.pone.0144316

Gingras, M., Paradis, I. and Berthod, F. (2003a). Nerve regeneration in a collagen-chitosan tissue-engineered skin transplanted on nude mice. Biomaterials 24, 1653-1661.

Gingras, M., Bergeron, J., Déry, J. et al. (2003b). In vitro development of a tissue-engineered model of peripheral nerve regeneration to study neurite growth. FASEB J 17, 2124-2126. doi:10.1096/fj.02-1180fje 
Gingras, M., Beaulieu, M.-M., Gagnon, V. et al. (2008). In vitro study of axonal migration and myelination of motor neurons in a three-dimensional tissue-engineered model. Glia 56, 354-364. doi:10.1002/glia.20617

Gonzalez-Andrades, M., Alonso-Pastor, L., Mauris, J. et al. (2016). Establishment of a novel in vitro model of stratified epithelial wound healing with barrier function. Sci Rep 6, 19395. doi:10.1038/srep19395

Groeber, F., Holeiter, M., Hampel, M. et al. (2011). Skin tissue engineering - In vivo and in vitro applications. Adv Drug Deliv Rev 63, 352-366. doi:10.1016/j.addr.2011.01.005

Groeber, F., Kahlig, A., Loff, S. et al. (2013). A bioreactor system for interfacial culture and physiological perfusion of vascularized tissue equivalents. Biotechnol $J$ 8, 308-316. doi:10.1002/biot.201200160

Groeber, F., Engelhardt, L., Lange, J. et al. (2016). A first vascularized skin equivalent as an alternative to animal experimentation. ALTEX 33, 415-422. doi:10.14573/altex.1604041

Guerra, L., Dellambra, E., Panacchia, L. and Paionni, E. (2009). Tissue engineering for damaged surface and lining epithelia: Stem cells, current clinical applications, and available engineered tissues. Tissue Eng Part B Rev 15, 91-112. doi:10.1089/ten.teb.2008.0418

Guo, L., Zhang, K. and Bing, Z. (2017). Application of a co-expression network for the analysis of aggressive and non-aggressive breast cancer cell lines to predict the clinical outcome of patients. Mol Med Rep 16, 7967-7978. doi:10.3892/ mmr.2017.7608

Gupta, S., Mukherjee, S., Syed, P. et al. (2017a). Evaluation of autoantibody signatures in meningioma patients using human proteome arrays. Oncotarget 8, 58443-58456. doi:10.18632/ oncotarget. 16997

Gupta, M. K., Behera, S. K., Dehury, B. and Mahapatra, N. (2017b). Identification and characterization of differentially expressed genes from human microglial cell samples infected with Japanese encephalitis virus. J Vector Borne Dis 54, 131-138.

Harris, P. A., di Francesco, F., Barisoni, D. et al. (1999). Use of hyaluronic acid and cultured autologous keratinocytes and fibroblasts in extensive burns. Lancet 353, 35-36.

Harrison, C. A., Layton, C. M., Hau, Z. et al. (2007). Transglutaminase inhibitors induce hyperproliferation and parakeratosis in tissue-engineered skin. Br J Dermatol 156, 247-257. doi:10.1111/j.1365-2133.2006.07641.x

Heilborn, J. D., Nilsson, M. F., Kratz, G. et al. (2003). The cathelicidin anti-microbial peptide LL-37 is involved in re-epithelialization of human skin wounds and is lacking in chronic ulcer epithelium. J Invest Dermatol 120, 379-389. doi:10.1046/j.1523-1747.2003.12069.x

Herman, I. M. and Leung, A. (2009). Creation of human skin equivalents for the in vitro study of angiogenesis in wound healing. Methods Mol Biol 467, 241-248. doi:10.1007/978-159745-241-0 14

Hettler, A., Werner, S., Eick, S. et al. (2013). A new in vitro model to study cellular responses after thermomechanical damage in monolayer cultures. PLoS One 8, e82635. doi:10.1371/journal.pone.0082635
Higgins, C. A., Chen, J. C., Cerise, J. E. et al. (2013). Microenvironmental reprogramming by three-dimensional culture enables dermal papilla cells to induce de novo human hair-follicle growth. Proc Natl Acad Sci U S A 110, 1967919688. doi:10.1073/pnas. 1309970110

Hill, D. S., Robinson, N. D., Caley, M. P. et al. (2015). A novel fully humanized $3 \mathrm{D}$ skin equivalent to model early melanoma invasion. Mol Cancer Ther 14, 2665-2673. doi:10.1158/15357163.MCT-15-0394

Hoffman, B. G., Williams, K. L., Tien, A. H. et al. (2006). Identification of novel genes and transcription factors involved in spleen, thymus and immunological development and function. Genes Immun 7, 101-112. doi:10.1038/sj.gene.6364270

Hönzke, S., Wallmeyer, L., Ostrowski, A. et al. (2016). Influence of Th2 cytokines on the cornified envelope, tight junction proteins, and $\beta$-defensins in filaggrin-deficient skin equivalents. J Invest Dermatol 136, 631-639. doi:10.1016/j. jid.2015.11.007

Hu, T., Kaluzhny, Y., Mun, G. C. et al. (2009). Intralaboratory and interlaboratory evaluation of the EpiDerm 3D human reconstructed skin micronucleus (RSMN) assay. Mutat Res 673, 100-108. doi:10.1016/j.mrgentox.2008.12.003

Huber, B., Link, A., Linke, K. et al. (2016). Integration of mature adipocytes to build-up a functional three-layered fullskin equivalent. Tissue Eng Part C Methods 22, 756-764. doi:10.1089/ten.TEC.2016.0141

Hudon, V., Berthod, F., Black, A. F. et al. (2003). A tissue-engineered endothelialized dermis to study the modulation of angiogenic and angiostatic molecules on capillary-like tube formation in vitro. Br J Dermatol 148, 1094-1104.

Imokawa, G. and Ishida, K. (2015). Biological mechanisms underlying the ultraviolet radiation-induced formation of skin wrinkling and sagging I: Reduced skin elasticity, highly associated with enhanced dermal elastase activity, triggers wrinkling and sagging. Int J Mol Sci 16, 7753-7775. doi:10.3390/ ijms 16047753

Inkeles, M. S., Scumpia, P. O., Swindell, W. R. et al. (2015). Comparison of molecular signatures from multiple skin diseases identifies mechanisms of immunopathogenesis. J Invest Dermatol 135, 151-159. doi:10.1038/jid.2014.352

Irons, R. F., Cahill, K. W., Rattigan, D. A. et al. (2018). Acceleration of diabetic wound healing with adipose-derived stem cells, endothelial-differentiated stem cells, and topical conditioned medium therapy in a swine model. J Vasc Surg 68, 115S-125S. doi:10.1016/j.jvs.2018.01.065

Ishiguro, T., Ohata, H., Sato, A. et al. (2017). Tumor-derived spheroids: Relevance to cancer stem cells and clinical applications. Cancer Sci 108, 283-289. doi:10.1111/cas.13155

Jean, J., Lapointe, M., Soucy, J. and Pouliot, R. (2009). Development of an in vitro psoriatic skin model by tissue engineering. J Dermatol Sci 53, 19-25. doi:10.1016/j. jdermsci.2008.07.009

Jung, E. C. and Maibach, H. I. (2015). Animal models for percutaneous absorption. J Appl Toxicol 35, 1-10. doi:10.1002/ jat.3004

Kabashima, K. and Nomura, T. (2017). Revisiting murine 
models for atopic dermatitis and psoriasis with multipolar cytokine axes. Curr Opin Immunol 48, 99-107. doi:10.1016/j. coi.2017.08.010

Kamsteeg, M., Bergers, M., de Boer, R. et al. (2011). Type 2 helper T-cell cytokines induce morphologic and molecular characteristics of atopic dermatitis in human skin equivalent. Am J Pathol 178, 2091-2099. doi:10.1016/j.ajpath.2011.01.037

Kao, B., Kadomatsu, K. and Hosaka, Y. (2009). Construction of synthetic dermis and skin based on a self-assembled peptide hydrogel scaffold. Tissue Eng Part A 15, 2385-2396. doi:10.1089/ten.tea.2008.0362

Kaufhold, S., Garbán, H. and Bonavida, B. (2016). Yin Yang 1 is associated with cancer stem cell transcription factors (SOX2, OCT4, BMI1) and clinical implication. J Exp Clin Cancer Res 35, 84. doi:10.1186/s13046-016-0359-2

Kerkar, S. P., Wang, Z.-F., Lasota, J. et al. (2016). MAGE-A is more highly expressed than NY-ESO-1 in a systematic immunohistochemical analysis of 3668 cases. J Immunother 39, 181-187. doi:10.1097/CJI.0000000000000119

Kim, M. and Park, H. J. (2016). Molecular mechanisms of skin aging and rejuvenation. In N. Shiomi (ed.), Molecular Mechanisms of the Aging Process and Rejuvenation (450). InTech. doi: $10.5772 / 62983$

Kimura, Y., Fujimura, C., Ito, Y. et al. (2015). Optimization of the IL-8 Luc assay as an in vitro test for skin sensitization. Toxicol In Vitro 29, 1816-1830. doi:10.1016/j.tiv.2015.07. 006

Klein, P., Sojka, M., Kucera, J. et al. (2018). A porcine model of skin wound infected with a polybacterial biofilm. Biofouling 34, 226-236. doi:10.1080/08927014.2018.1425684

Klettner, A., Tahmaz, N., Dithmer, M. et al. (2014). Effects of aflibercept on primary RPE cells: Toxicity, wound healing, uptake and phagocytosis. Br J Ophthalmol 98, 1448-1452. doi:10.1136/bjophthalmol-2014-305105

Koppenol, D. C., Vermolen, F. J., Niessen, F. B. et al. (2017). A biomechanical mathematical model for the collagen bundle distribution-dependent contraction and subsequent retraction of healing dermal wounds. Biomech Model Mechanobiol 16, 345-361. doi:10.1007/s10237-016-0821-2

Kranthi Kumar, K., Uma Devi, B. and Neeraja, P. (2017). Integration of in silico approaches to determination of endocrine-disrupting perfluorinated chemicals binding potency with steroidogenic acute regulatory protein. Biochem Biophys Res Commun 491, 1007-1014. doi:10.1016/j. bbrc.2017.07.168

Krejsgaard, T., Kopp, K., Ralfkiaer, E. et al. (2010). A novel xenograft model of cutaneous T-cell lymphoma. Exp Dermatol 19, 1096-1102. doi:10.1111/j.1600-0625.2010.01138.x

Lan, R., Geng, H., Hwang, Y. et al. (2010). A novel wounding device suitable for quantitative biochemical analysis of wound healing and regeneration of cultured epithelium. Wound Repair Regen 18, 159-167. doi:10.1111/j.1524-475X. 2010.00576.x

Larson, A. R., Lee, C.-W., Lezcano, C. et al. (2014). Melanoma spheroid formation involves laminin-associated vas- culogenic mimicry. Am J Pathol 184, 71-78. doi:10.1016/j. ajpath.2013.09.020

LaRue, K. E., Khalil, M. and Freyer, J. P. (2004). Microenvironmental regulation of proliferation in multicellular spheroids is mediated through differential expression of cyclin-dependent kinase inhibitors. Cancer Res 64, 1621-1631.

Lee, D.-Y. and Cho, K.-H. (2005). The effects of epidermal keratinocytes and dermal fibroblasts on the formation of cutaneous basement membrane in three-dimensional culture systems. Arch Dermatol Res 296, 296-302. doi:10.1007/ s00403-004-0529-5

Lee, J., Wang, Y.-L., Ren, F. Lele, T. P. (2010). Stamp wound assay for studying coupled cell migration and cell debris clearance. Langmuir 26, 16672-16676. doi:10.1021/la103542y

Lee, V. K. and Dai, G. (2017). Printing of three-dimensional tissue analogs for regenerative medicine. Ann Biomed Eng 45, 115-131. doi:10.1007/s10439-016-1613-7

Lee, Y.-S., Hsu, T., Chiu, W.-C. et al. (2016). Keloid-derived, plasma/fibrin-based skin equivalents generate de novo dermal and epidermal pathology of keloid fibrosis in a mouse model. Wound Repair Regen 24, 302-316. doi:10.1111/wrr. 12397

Li, A., Estigoy, C., Raftery, M. et al. (2013). Heart research advances using database search engines, Human Protein Atlas and the Sydney Heart Bank. Heart Lung Circ 22, 819-826. doi:10.1016/j.hlc.2013.06.006

Li, Q., Frank, M., Akiyama, M. et al. (2011). Abca12-mediated lipid transport and Snap29-dependent trafficking of lamellar granules are crucial for epidermal morphogenesis in a zebrafish model of ichthyosis. Dis Model Mech 4, 777-785. doi: $10.1242 / \mathrm{dmm} .007146$

Li, Q. and Uitto, J. (2014). Zebrafish as a model system to study skin biology and pathology. J Invest Dermatol 134, 1-6. doi:10.1038/jid.2014.182

Liang, C.-C., Park, A. Y. and Guan, J.-L. (2007). In vitro scratch assay: A convenient and inexpensive method for analysis of cell migration in vitro. Nat Protoc 2, 329-333. doi:10.1038/ nprot. 2007.30

Liang, Y., Sarkar, M. K., Tsoi, L. C. et al. (2017). Psoriasis: A mixed autoimmune and autoinflammatory disease. Curr Opin Immunol 49, 1-8. doi:10.1016/j.coi.2017.07.007

Lightfoot, S. E., Tamamoto, K. A., Nguyen, H. et al. (2018). Biomaterials 3D biomaterial matrix to support long term, full thickness, immuno-competent human skin equivalents with nervous system components. Biomaterials, Epub ahead of print. doi:10.1016/j.biomaterials.2018.04.044

Lindskog, C., Korsgren, O., Pontén, F. et al. (2012). Novel pancreatic beta cell-specific proteins: Antibody-based proteomics for identification of new biomarker candidates. $J$ Proteomics 75, 2611-2620. doi:10.1016/j.jprot.2012.03.008

Liu, D., Liu, P., Cao, L. et al. (2017a). Screening the key genes of hepatocellular adenoma via microarray analysis of DNA expression and methylation profiles. Oncol Lett 14, 39753980. doi:10.3892/ol.2017.6673

Liu, L., Zhang, Y. and Cao, W. (2017b). Highly expressed lncRNALOC730101 promotes lung cancer cell growth through 
Wnt canonical pathway. Biochem Biophys Res Commun 493, 992-997. doi:10.1016/j.bbrc.2017.09.104

Liu, M., Saeki, K., Matsunobu, T. et al. (2014). 12-Hydroxyheptadecatrienoic acid promotes epidermal wound healing by accelerating keratinocyte migration via the BLT2 receptor. $J$ Exp Med 211, 1063-1078. doi:10.1084/jem.20132063

Liu, N., Huang, S., Yao, B. et al. (2016). 3D bioprinting matrices with controlled pore structure and release function guide in vitro self-organization of sweat gland. Sci Rep 6, 34410. doi:10.1038/srep34410

Llames, S. G., Del Rio, M., Larcher, F. et al. (2004). Human plasma as a dermal scaffold for the generation of a completely autologous bioengineered skin. Transplantation 77, 350355. doi:10.1097/01.TP.0000112381.80964.85

Ma, Q., Wu, X., Wu, J. et al. (2017). SERP1 is a novel marker of poor prognosis in pancreatic ductal adenocarcinoma patients via anti-apoptosis and regulating SRPRB/NF- $\kappa \mathrm{B}$ axis. Int J Oncol 51, 1104-1114. doi:10.3892/ijo.2017.4111

MacLeod, A. S. and Havran, W. L. (2011). Functions of skin-resident $\gamma \delta$ T cells. Cell Mol Life Sci 68, 2399-2408. doi:10.1007/s00018-011-0702-x

Marconi, A., Quadri, M., Saltari, A. and Pincelli, C. (2018). Progress in melanoma modelling in vitro. Exp Dermatol 27, 578-586. doi:10.1111/exd.13670

Marino, D., Luginbühl, J., Scola, S. et al. (2014). Bioengineering dermo-epidermal skin grafts with blood and lymphatic capillaries. Sci Transl Med 6, 221ra14. doi:10.1126/scitranslmed. 3006894

Marquardt, Y., Amann, P. M., Heise, R. et al. (2015). Characterization of a novel standardized human three-dimensional skin wound healing model using non-sequential fractional ultrapulsed $\mathrm{CO}_{2}$ laser treatments. Lasers Surg Med 47, 257265. doi:10.1002/1sm.22341

Marston, W. A., Hanft, J., Norwood, P. et al. (2003). The efficacy and safety of Dermagraft in improving the healing of chronic diabetic foot ulcers: Results of a prospective randomized trial. Diabetes Care 26, 1701-1705.

Martínez-Santamaría, L., Guerrero-Aspizua, S. and Del Río, M. (2012). Skin bioengineering: Preclinical and clinical applications. Actas Dermosifiliogr 103, 5-11. doi:10.1016/j.adengl. 2011.03.016

Martorina, F., Casale, C., Urciuolo, F. et al. (2017). In vitro activation of the neuro-transduction mechanism in sensitive organotypic human skin model. Biomaterials 113, 217-229. doi:10.1016/j.biomaterials.2016.10.051

Matsubayashi, Y. and Millard, T. H. (2016). Analysis of the molecular mechanisms of reepithelialization in Drosophila embryos. Adv Wound Care 5, 243-250. doi:10.1089/ wound.2014.0549

Maurelli, R., Zambruno, G., Guerra, L. et al. (2006). Inactivation of p16 INK4a (inhibitor of cyclin-dependent kinase 4A) immortalizes primary human keratinocytes by maintaining cells in the stem cell compartment. FASEB J 20, 1516-1518. doi:10.1096/fj.05-4480fje

Mazarei, G., Neal, S. J., Becanovic, K. et al. (2010). Expression analysis of novel striatal-enriched genes in Huntington dis- ease. Hum Mol Genet 19, 609-622. doi:10.1093/hmg/ddp527

Meier, F., Nesbit, M., Hsu, M. Y. et al. (2000). Human melanoma progression in skin reconstructs : Biological significance of bFGF. Am J Pathol 156, 193-200. doi:10.1016/S00029440(10)64719-0

Mendoza-Garcia, J., Sebastian, A., Alonso-Rasgado, T. and Bayat, A. (2015). Optimization of an ex vivo wound healing model in the adult human skin: Functional evaluation using photodynamic therapy. Wound Repair Regen 23, 685-702. doi:10.1111/wrr. 12325

Menke, N. B., Cain, J. W., Reynolds, A. et al. (2010). An in silico approach to the analysis of acute wound healing. Wound Repair Regen 18, 105-113. doi:10.1111/j.1524-475X. 2009.00549.x

Mertsching, H., Walles, T., Hofmann, M. et al. (2005). Engineering of a vascularized scaffold for artificial tissue and organ generation. Biomaterials 26, 6610-6617. doi:10.1016/j. biomaterials.2005.04.048

Meyvantsson, I. and Beebe, D. J. (2008). Cell culture models in microfluidic systems. Annu Rev Anal Chem (Palo Alto Calif) 1, 423-449. doi:10.1146/annurev.anchem.1.031207.113042

Mi, Q., Rivière, B., Clermont, G. et al. (2007). Agent-based model of inflammation and wound healing: Insights into diabetic foot ulcer pathology and the role of transforming growth factor- $\beta 1$. Wound Repair Regen 15, 671-682. doi:10.1111/j.1524-475X.2007.00271.x

Molinari, J., Ruszova, E., Velebny, V. and Robert, L. (2008). Effect of advanced glycation endproducts on gene expression profiles of human dermal fibroblasts. Biogerontology 9, 177. doi:10.1007/s10522-008-9129-7

Monfort, A., Soriano-Navarro, M., García-Verdugo, J. M. and Izeta, A. (2013). Production of human tissue-engineered skin trilayer on a plasma-based hypodermis. J Tissue Eng Regen Med 7, 479-490. doi:10.1002/term.548

Mori, N., Morimoto, Y. and Takeuchi, S. (2017). Skin integrated with perfusable vascular channels on a chip. Biomaterials 116, 48-56. doi:10.1016/j.biomaterials.2016.11.031

Müller, I. and Kulms, D. (2018). A 3D organotypic melanoma spheroid skin model. J Vis Exp 135, e57500. doi:10.3791/57500

Murphree, R. W. (2017). Impairments in skin integrity. Nurs Clin North Am 52, 405-417. doi:10.1016/j.cnur.2017.04.008

Nagaraja, S., Chen, L., Zhou, J. et al. (2017). Predictive analysis of mechanistic triggers and mitigation strategies for pathological scarring in skin wounds. J Immunol 198, 832841. doi:10.4049/jimmunol.1601273

Ng, W. L., Wang, S., Yeong, W. Y. and Naing, M. W. (2016). Skin bioprinting: Impending reality or fantasy? Trends Biotechnol 34, 689-699. doi:10.1016/j.tibtech.2016.04.006

Nieto-Jiménez, C., Alcaraz-Sanabria, A., Páez, R. et al. (2017). DNA-damage related genes and clinical outcome in hormone receptor positive breast cancer. Oncotarget 8, 62834-62841. doi:10.18632/oncotarget.10886

O’Connor, N., Mulliken, J., Banks-Schlegel, S. et al. (1981). Grafting of burns with cultured epithelium prepared from autologous epidermal cells. Lancet 317, 75-78. doi:10.1016/ S0140-6736(81)90006-4 
Obrigkeit, D. H., Jugert, F. K., Beermann, T. et al. (2009). Effects of photodynamic therapy evaluated in a novel three-dimensional squamous cell carcinoma organ construct of the skin. Photochem Photobiol 85, 272-278. doi:10.1111/j.17511097.2008.00432.x

Ojeh, N., Akgül, B., Tomic-Canic, M. et al. (2017). In vitro skin models to study epithelial regeneration from the hair follicle. PLoS One 12, e0174389. doi:10.1371/journal.pone.0174389

Okano, Y., Masaki, H. and Sakurai, H. (2002). Dysfunction of dermal fibroblasts induced by advanced glycation end-products (AGEs) and the contribution of a nonspecific interaction with cell membrane and AGEs. J Dermatol Sci 29, 171-180.

Ostyn, P., El Machhour, R., Begard, S. et al. (2014). Transient TNF regulates the self-renewing capacity of stem-like label-retaining cells in sphere and skin equivalent models of melanoma. Cell Commun Signal 12, 52. doi:10.1186/s12964014-0052-z

Otsuka, A., Nomura, T., Rerknimitr, P. et al. (2017). The interplay between genetic and environmental factors in the pathogenesis of atopic dermatitis. Immunol Rev 278, 246-262. doi:10.1111/imr.12545

Ozerov, I. V, Lezhnina, K. V, Izumchenko, E. et al. (2016). In silico pathway activation network decomposition analysis (iPANDA) as a method for biomarker development. Nat Commun 7, 13427. doi:10.1038/ncomms 13427

Pageon, H. and Asselineau, D. (2005). An in vitro approach to the chronological aging of skin by glycation of the collagen: The biological effect of glycation on the reconstructed skin model. Ann N Y Acad Sci 1043, 529-532. doi:10.1196/ annals. 1333.060

Pageon, H. (2010). Reaction of glycation and human skin: The effects on the skin and its components, reconstructed skin as a model. Pathol Biol (Paris) 58, 226-231. doi:10.1016/j. patbio.2009.09.009

Pageon, H., Zucchi, H., Dai, Z. et al. (2015). Biological effects induced by specific advanced glycation end products in the reconstructed skin model of aging. Biores Open Access 4, 5464. doi:10.1089/biores.2014.0053

Pageon, H., Zucchi, H., Rousset, F. et al. (2017). Glycation stimulates cutaneous monocyte differentiation in reconstructed skin in vitro. Mech Ageing Dev 162, 18-26. doi:10.1016/j. mad.2017.02.001

Panacchia, L., Dellambra, E., Bondanza, S. et al. (2010). Nonirradiated human fibroblasts and irradiated 3T3-J2 murine fibroblasts as a feeder layer for keratinocyte growth and differentiation in vitro on a fibrin substrate. Cells Tissues Organs 191, 21-35. doi:10.1159/000225956

Paolini, C., Orecchia, A., Failla, C. M. et al. (2013). Skin equivalents: A tool for the discovery and validation of pharmacodynamic biomarkers. Cancer Invest 31, 60-66. doi:10.3109/0 7357907.2012.749269

Patel, G. K., Yee, C. L., Terunuma, A. et al. (2012). Identification and characterization of tumor-initiating cells in human primary cutaneous squamous cell carcinoma. J Invest Dermatol 132, 401-409. doi:10.1038/jid.2011.317

Pellegrini, G., Ranno, R., Stracuzzi, G. et al. (1999). The con- trol of epidermal stem cells (holoclones) in the treatment of massive full-thickness burns with autologous keratinocytes cultured on fibrin. Transplantation 68, 868-879.

Pinto, J. A., Rolfo, C., Raez, L. E. et al. (2017). In silico evaluation of DNA Damage Inducible Transcript 4 gene (DDIT4) as prognostic biomarker in several malignancies. Sci Rep 7, 1526. doi:10.1038/s41598-017-01207-3

Ponec, M., Weerheim, A., Kempenaar, J. et al. (1997). The formation of competent barrier lipids in reconstructed human epidermis requires the presence of vitamin C. J Invest Dermatol 109, 348-355.

Ponec, M., El Ghalbzouri, A., Dijkman, R. et al. (2004). Endothelial network formed with human dermal microvascular endothelial cells in autologous multicellular skin substitutes. Angiogenesis 7, 295-305. doi:10.1007/s10456-004-6315-3

Puujalka, E., Heinz, M., Hoesel, B. et al. (2016). Opposing roles of $\mathrm{JNK}$ and p38 in lymphangiogenesis in melanoma. $J$ Invest Dermatol 136, 967-977. doi:10.1016/j.jid.2016.01.020

Python, F., Goebel, C. and Aeby, P. (2007). Assessment of the U937 cell line for the detection of contact allergens. Toxicol Appl Pharmacol 220, 113-124. doi:10.1016/j.taap. 2006.12.026

Ramadan, Q. and Ting, F. C. W. (2016). In vitro micro-physiological immune-competent model of the human skin. Lab Chip 16, 1899-1908. doi:10.1039/c61c00229c

Régnier, M., Staquet, M. J., Schmitt, D. and Schmidt, R. (1997). Integration of Langerhans cells into a pigmented reconstructed human epidermis. J Invest Dermatol 109, 510-512.

Reijnders, C. M. A., van Lier, A., Roffel, S. et al. (2015). Development of a full-thickness human skin equivalent in vitro model derived from TERT-immortalized keratinocytes and fibroblasts. Tissue Eng Part A 21, 2448-2459. doi:10.1089/ ten.TEA.2015.0139

Reisinger, K., Blatz, V., Brinkmann, J. et al. (2018). Validation of the 3D Skin Comet assay using full thickness skin models: Transferability and reproducibility. Mutat Res 827, 27-41. doi:10.1016/j.mrgentox.2018.01.003

Rheinwald, J. G. and Green, H. (1975). Serial cultivation of strains of human epidermal keratinocytes: The formation of keratinizing colonies from single cells. Cell 6, 331-343. doi:10.1172/JCI200420761

Rheinwald, J. G. and Beckett, M. A. (1981). Tumorigenic keratinocyte lines requiring anchorage and fibroblast support cultured from human squamous cell carcinomas. Cancer Res 41, 1657-1663.

Richardson, R., Slanchev, K., Kraus, C. et al. (2013). Adult zebrafish as a model system for cutaneous wound-healing research. J Invest Dermatol 133, 1655-1665. doi:10.1038/ jid.2013.16

Richter, A., Schmucker, S. S., Esser, P. R. et al. (2013). Human $\mathrm{T}$ cell priming assay (hTCPA) for the identification of contact allergens based on naive T cells and DC - IFN- $\gamma$ and TNF- $\alpha$ readout. Toxicol In Vitro 27, 1180-1185. doi:10.1016/j.tiv.2012. 08.007

Ridky, T. W., Chow, J. M., Wong, D. J. and Khavari, P. A. (2010). Invasive three-dimensional organotypic neoplasia 
from multiple normal human epithelia. Nat Med 16, 14501455. doi:10.1038/nm.2265

Roberts, D. W. and Patlewicz, G. (2018). Non-animal assessment of skin sensitization hazard: Is an integrated testing strategy needed, and if so what should be integrated? $J$ Appl Toxicol 38, 41-50. doi:10.1002/jat.3479

Rocco, P., Cilurzo, F., Minghetti, P. et al. (2017). Molecular dynamics as a tool for in silico screening of skin permeability. Eur J Pharm Sci 106, 328-335. doi:10.1016/j. ejps.2017.06.020

Rohringer, S., Hofbauer, P., Schneider, K. H. et al. (2014). Mechanisms of vasculogenesis in 3D fibrin matrices mediated by the interaction of adipose-derived stem cells and endothelial cells. Angiogenesis 17, 921-933. doi:10.1007/ s10456-014-9439-0

Ronfard, V., Rives, J. M., Neveux, Y. et al. (2000). Long-term regeneration of human epidermis on third degree burns transplanted with autologous cultured epithelium grown on a fibrin matrix. Transplantation 70, 1588-1598.

Sa, S. M., Valdez, P. A., Wu, J. et al. (2007). The effects of IL-20 subfamily cytokines on reconstituted human epidermis suggest potential roles in cutaneous innate defense and pathogenic adaptive immunity in psoriasis. J Immunol 178, 2229-2240.

Sachs, N. and Clevers, H. (2014). Organoid cultures for the analysis of cancer phenotypes. Curr Opin Genet Dev 24, 6873. doi:10.1016/j.gde.2013.11.012

Safferling, K., Sütterlin, T., Westphal, K. et al. (2013). Wound healing revised: A novel reepithelialization mechanism revealed by in vitro and in silico models. J Cell Biol 203, 691709. doi:10.1083/jcb.201212020

Sakaguchi, H., Ashikaga, T., Miyazawa, M. et al. (2006). Development of an in vitro skin sensitization test using human cell lines; human cell line activation test (h-CLAT). II. An inter-laboratory study of the h-CLAT. Toxicol In Vitro 20, 774-784. doi:10.1016/j.tiv.2005.10.014

Sato, T., Stange, D. E., Ferrante, M. et al. (2011). Long-term expansion of epithelial organoids from human colon, adenoma, adenocarcinoma, and Barrett's epithelium. Gastroenterology 141, 1762-1772. doi:10.1053/j.gastro.2011.07.050

Saul, L., Ilieva, K. M., Bax, H. J. et al. (2016). IgG subclass switching and clonal expansion in cutaneous melanoma and normal skin. Sci Rep 6, 29736. doi:10.1038/srep29736

Scafuri, B., Marabotti, A., Carbone, V. et al. (2016). A theoretical study on predicted protein targets of apple polyphenols and possible mechanisms of chemoprevention in colorectal cancer. Sci Rep 6, 32516. doi:10.1038/srep32516

Schanz, J., Pusch, J., Hansmann, J. et al. (2010). Vascularised human tissue models: A new approach for the refinement of biomedical research. J Biotechnol 148, 56-63. doi:10.1016/j. jbiotec.2010.03.015

Schechner, J. S., Crane, S. K., Wang, F. et al. (2003). Engraftment of a vascularized human skin equivalent. FASEB J 17, 2250-2256. doi:10.1096/fj.03-0257com

Scherfer, C., Han, V. C., Wang, Y. et al. (2013). Autophagy drives epidermal deterioration in a Drosophila model of tis- sue aging. Aging (Albany NY) 5, 276-287. doi:10.18632/aging. 100549

Schneider, M. R. (2012). Genetic mouse models for skin research: Strategies and resources. Genesis 50, 652-664. doi:10. 1002/dvg.22029

Schugart, R. C., Friedman, A., Zhao, R. and Sen, C. K. (2008). Wound angiogenesis as a function of tissue oxygen tension: A mathematical model. Proc Natl Acad Sci U S A 105, 26282633. doi:10.1073/pnas.0711642105

Seneschal, J., Clark, R. A., Gehad, A. et al. (2012). Human epidermal Langerhans cells maintain immune homeostasis in skin by activating skin resident regulatory T cells. Immunity 36, 873-884. doi:10.1016/j.immuni.2012.03.018

Shan, Y.-S., Hsu, H.-P., Lai, M.-D. et al. (2017). Cyclin D1 overexpression correlates with poor tumor differentiation and prognosis in gastric cancer. Oncol Lett 14, 4517-4526. doi:10.3892/ol.2017.6736

Song, J. W. and Munn, L. L. (2011). Fluid forces control endothelial sprouting. Proc Natl Acad Sci US A 108, 1534215347. doi:10.1073/pnas.1105316108

Sriram, G., Bigliardi, P. L. and Bigliardi-Qi, M. (2015). Fibroblast heterogeneity and its implications for engineering organotypic skin models in vitro. Eur J Cell Biol 94, 483-512. doi:10.1016/j.ejcb.2015.08.001

Sriram, G., Alberti, M., Dancik, Y. et al. (2018). Full-thickness human skin-on-chip with enhanced epidermal morphogenesis and barrier function. Mater Today 21, 326-340. doi:10.1016/j.mattod.2017.11.002

Stamm, A., Reimers, K., Strauß, S. et al. (2016). In vitro wound healing assays - State of the art. BioNanoMaterials 17. doi:10. 1515/bnm-2016-0002

Stenn, K. S. and Cotsarelis, G. (2005). Bioengineering the hair follicle: Fringe benefits of stem cell technology. Curr Opin Biotechnol 16, 493-497. doi:10.1016/j.copbio.2005.08.002

Stevenson, A. J., Ager, E. I., Proctor, M. A. et al. (2018). Mechanism of action of the third generation benzopyrans and evaluation of their broad anti-cancer activity in vitro and in vivo. Sci Rep 8, 5144. doi:10.1038/s41598-018-22882-w

Sticker, D., Lechner, S., Jungreuthmayer, C. et al. (2017). Microfluidic migration and wound healing assay based on mechanically induced injuries of defined and highly reproducible areas. Anal Chem 89, 2326-2333. doi:10.1021/acs. analchem.6b03886

Sullivan, T. P., Eaglstein, W. H., Davis, S. C. and Mertz, P. (2001). The pig as a model for human wound healing. Wound Repair Regen 9, 66-76.

Sun, T., Adra, S., Smallwood, R. et al. (2009). Exploring hypotheses of the actions of TGF-betal in epidermal wound healing using a 3D computational multiscale model of the human epidermis. PLoS One 4, e8515. doi:10.1371/journal. pone. 0008515

Tartarini, D. and Mele, E. (2015). Adult stem cell therapies for wound healing: Biomaterials and computational models. Front Bioeng Biotechnol 3, 206. doi:10.3389/ fbioe.2015.00206

Terry, J. and Neethirajan, S. (2014). A novel microfluidic 
wound model for testing antimicrobial agents against Staphylococcus pseudintermedius biofilms. J Nanobiotechnology 12, 1. doi:10.1186/1477-3155-12-1

Thode, C., Woetmann, A., Wandall, H. H. et al. (2015). Malignant $\mathrm{T}$ cells secrete galectins and induce epidermal hyperproliferation and disorganized stratification in a skin model of cutaneous T-cell lymphoma. J Invest Dermatol 135, 238-246. doi:10.1038/jid.2014.284

Thul, P. J. and Lindskog, C. (2018). The human protein atlas: A spatial map of the human proteome. Protein Sci 27, 233-244. doi:10.1002/pro.3307

Tiwari, A., Pattnaik, N., Mohanty Jaiswal, A. and Dixit, M. (2017). Increased FSHD region gene1 expression reduces in vitro cell migration, invasion, and angiogenesis, ex vivo supported by reduced expression in tumors. Biosci Rep 37. doi:10.1042/BSR20171062

Tjabringa, G., Bergers, M., van Rens, D. et al. (2008). Development and validation of human psoriatic skin equivalents. Am J Pathol 173, 815-823. doi:10.2353/ajpath.2008.080173

Topman, G., Sharabani-Yosef, O. and Gefen, A. (2012). A standardized objective method for continuously measuring the kinematics of cultures covering a mechanically damaged site. Med Eng Phys 34, 225-232. doi:10.1016/j.medengphy.2011.07.014

Tremblay, P.-L., Hudon, V., Berthod, F. et al. (2005). Inosculation of tissue-engineered capillaries with the host's vasculature in a reconstructed skin transplanted on mice. Am J Transplant 5, 1002-1010. doi:10.1111/j.1600-6143.2005.00790.x

Trottier, V., Marceau-Fortier, G., Germain, L. et al. (2008). IFATS collection: Using human adipose-derived stem/stromal cells for the production of new skin substitutes. Stem Cells 26, 2713-2723. doi:10.1634/stemcells.2008-0031

van den Bogaard, E. H., Tjabringa, G. S., Joosten, I. et al. (2014). Crosstalk between keratinocytes and T cells in a 3D microenvironment: A model to study inflammatory skin diseases. $J$ Invest Dermatol 134, 719-727. doi:10.1038/jid.2013.417

van den Broek, L. J., Bergers, L. I. J. C., Reijnders, C. M. A. and Gibbs, S. (2017). Progress and future prospectives in skin-on-chip development with emphasis on the use of different cell types and technical challenges. Stem Cell Rev Rep 13, 418-429. doi:10.1007/s12015-017-9737-1

van der Meer, A. D., Poot, A. A., Feijen, J. and Vermes, I. (2010). Analyzing shear stress-induced alignment of actin filaments in endothelial cells with a microfluidic assay. Biomicrofluidics 4, 11103. doi:10.1063/1.3366720

van de Wetering, M., Francies, H. E., Francis, J. M. et al. (2015). Prospective derivation of a living organoid biobank of colorectal cancer patients. Cell 161, 933-945. doi:10.1016/j. cell.2015.03.053

van Rooijen, E., Fazio, M. and Zon, L. I. (2017). From fish bowl to bedside: The power of zebrafish to unravel melanoma pathogenesis and discover new therapeutics. Pigment Cell Melanoma Res 30, 402-412. doi:10.1111/pcmr. 12592

van Vliet, E. (2017). State-of-the-art and new options to assess T cell activation by skin sensitizers: Cosmetics Europe Workshop. ALTEX 35, 179-192. doi:10.14573/altex.1709011
Verbridge, S. S., Chakrabarti, A., DelNero, P. et al. (2013). Physicochemical regulation of endothelial sprouting in a 3D microfluidic angiogenesis model. J Biomed Mater Res A 101, 2948-2956. doi:10.1002/jbm.a.34587

Veves, A., Falanga, V., Armstrong, D. G. et al. (2001). Graftskin, a human skin equivalent, is effective in the management of noninfected neuropathic diabetic foot ulcers: A prospective randomized multicenter clinical trial. Diabetes Care 24, 290-295.

Vijayavenkataraman, S., Shuo, Z., Fuh, J. Y. H. and Lu, W. F. (2017). Design of three-dimensional scaffolds with tunable matrix stiffness for directing stem cell lineage specification: An in silico study. Bioeng (Basel) 4, 66. doi:10.3390/bioengineering4030066

Vörsmann, H., Groeber, F., Walles, H. et al. (2013). Development of a human three-dimensional organotypic skin-melanoma spheroid model for in vitro drug testing. Cell Death Dis 4, e719. doi:10.1038/cddis.2013.249

Wallmeyer, L., Dietert, K., Sochorová, M. et al. (2017). TSLP is a direct trigger for $\mathrm{T}$ cell migration in filaggrin-deficient skin equivalents. Sci Rep 7, 774. doi:10.1038/s41598-017-00670-2

Wang, J. X., Fukunaga-Kalabis, M. and Herlyn, M. (2016). Crosstalk in skin: Melanocytes, keratinocytes, stem cells, and melanoma. J Cell Commun Signal 10, 191-196. doi:10.1007/ s12079-016-0349-3

Wang, Y., Zheng, C., Wang, X. et al. (2017a). Proteomic profile-based screening of potential protein biomarkers in the urine of patients with nephrotic syndrome. Mol Med Rep 16, 6276-6284. doi:10.3892/mmr.2017.7329

Wang, S., Fan, W., Wan, B. et al. (2017b). Characterization of long noncoding RNA and messenger RNA signatures in melanoma tumorigenesis and metastasis. PLoS One 12, e0172498. doi:10.1371/journal.pone.0172498

Weeber, F., Ooft, S. N., Dijkstra, K. K. and Voest, E. E. (2017). Tumor organoids as a pre-clinical cancer model for drug discovery. Cell Chem Biol 24, 1092-1100. doi:10.1016/j. chembiol.2017.06.012

Wei, Y., Chen, F., Zhang, T. et al. (2015). A tubing-free microfluidic wound healing assay enabling the quantification of vascular smooth muscle cell migration. Sci Rep 5, 14049. doi:10.1038/srep14049

Whitesides, G. M. (2006). The origins and the future of microfluidics. Nature 442, 368-373. doi:10.1038/nature05058

Woo, S.-H., Lumpkin, E. A. and Patapoutian, A. (2015). Merkel cells and neurons keep in touch. Trends Cell Biol 25, 74-81. doi:10.1016/j.tcb.2014.10.003

Wu, S., Wu, F. and Jiang, Z. (2017). Identification of hub genes, key miRNAs and potential molecular mechanisms of colorectal cancer. Oncol Rep 38, 2043-2050. doi:10.3892/ or.2017.5930

Wufuer, M., Lee, G., Hur, W. et al. (2016). Skin-on-a-chip model simulating inflammation, edema and drug-based treatment. Sci Rep 6, 37471. doi:10.1038/srep37471

Xu, W., Jong Hong, S., Jia, S. et al. (2012). Application of a partial-thickness human ex vivo skin culture model in cutaneous wound healing study. Lab Invest 92, 584-599. doi:10.1038/ labinvest.2011.184 
Yaar, M. and Gilchrest, B. A. (2007). Photoageing: Mechanism, prevention and therapy. Br J Dermatol 157, 874-887. doi:10.1111/j.1365-2133.2007.08108.x

Yanagi, T., Nagai, K., Shimizu, H. and Matsuzawa, S. I. (2017). Melanoma antigen A12 regulates cell cycle via tumor suppressor p21 expression. Oncotarget 8, 68448-68459. doi:10.18632/oncotarget.19497

Young, S. L., Savaris, R. F., Lessey, B. A. et al. (2017). Effect of randomized serum progesterone concentration on secretory endometrial histologic development and gene expression. Hum Reprod 32, 1903-1914. doi:10.1093/humrep/dex252

Yue, P. Y. K., Leung, E. P., Mak, N. K. and Wong, R. N. (2010). A simplified method for quantifying cell migration/wound healing in 96-well plates. J Biomol Screen 15, 427-433. doi: $10.1177 / 1087057110361772$

Zhang, C., Zhai, W., Xie, Y. et al. (2013a). Mesenchymal stem cells derived from breast cancer tissue promote the proliferation and migration of the MCF-7 cell line in vitro. Oncol Lett 6, 1577-1582. doi:10.3892/ol.2013.1619

Zhang, C., Jang, S., Amadi, O. C. et al. (2013b). A sensitive chemotaxis assay using a novel microfluidic device. Biomed Res Int 2013, 373569. doi:10.1155/2013/373569

Zhang, L., Ma, S., Wang, H. et al. (2017a). Identification of pathogenic genes related to rheumatoid arthritis through integrated analysis of DNA methylation and gene expression profiling. Gene 634, 62-67. doi:10.1016/j.gene.2017.08.032

Zhang, Y., Dang, Y.-W., Wang, X. et al. (2017b). Comprehensive analysis of long non-coding RNA PVT1 gene interaction regulatory network in hepatocellular carcinoma using gene microarray and bioinformatics. Am J Transl Res 9, 3904-3917.

Zhang, X., Huo, L., Jin, H. et al. (2017c). Anti-cancer activity of Annexin $\mathrm{V}$ in murine melanoma model by suppressing tumor angiogenesis. Oncotarget 8, 42602-42612. doi:10.18632/oncotarget. 16645

Zhang, Z. and Michniak-Kohn, B. B. (2012). Tissue engineered human skin equivalents. Pharmaceutics 4, 26-41. doi:10.3390/pharmaceutics4010026

Zhao, F., Pathi, P., Grayson, W. et al. (2008). Effects of oxygen transport on 3-D human mesenchymal stem cell metabolic activity in perfusion and static cultures: Experiments and mathematical model. Biotechnol Prog 21, 1269-1280. doi:10.1021/bp0500664

Zong, S., Li, W., Li, H. et al. (2017). Identification of hypoxia-regulated angiogenic genes in colorectal cancer. Biochem Biophys Res Commun 493, 461-467. doi:10.1016/j. bbrc.2017.08.169

\section{Conflict of interest}

The authors declare that they have no conflicts of interest.

\section{Acknowledgements}

The authors wish to thank Maurizio Inzillo for artwork. This work was supported by grants from the Italian Ministry of Health "Ricerca Corrente". 